\title{
Modeling the formation and properties of traditional and non-traditional secondary organic aerosol: problem formulation and application to aircraft exhaust
}

\author{
S. H. Jathar ${ }^{1,2}$, M. A. Miracolo ${ }^{2}$, A. A. Presto ${ }^{2,3}$, N. M. Donahue ${ }^{1,2,4}$, P. J. Adams ${ }^{1,2,5}$, and A. L. Robinson ${ }^{1,2,3}$ \\ ${ }^{1}$ Engineering and Public Policy, Carnegie Mellon University, Pittsburgh PA, USA \\ ${ }^{2}$ Center for Atmospheric Particle Studies, Carnegie Mellon University, Pittsburgh PA, USA \\ ${ }^{3}$ Mechanical Engineering, Carnegie Mellon University, Pittsburgh PA, USA \\ ${ }^{4}$ Chemical Engineering, Carnegie Mellon University, Pittsburgh PA, USA \\ ${ }^{5}$ Civil and Environmental Engineering, Carnegie Mellon University, Pittsburgh PA, USA
}

Correspondence to: A. L. Robinson (alr@andrew.cmu.edu)

Received: 21 March 2012 - Published in Atmos. Chem. Phys. Discuss.: 18 April 2012

Revised: 30 August 2012 - Accepted: 1 September 2012 - Published: 4 October 2012

\begin{abstract}
We present a methodology to model secondary organic aerosol (SOA) formation from the photo-oxidation of unspeciated low-volatility organics (semi-volatile and intermediate volatile organic compounds) emitted by combustion systems. It is formulated using the volatility basis-set approach. Unspeciated low-volatility organics are classified by volatility and then allowed to react with the hydroxyl radical. The new methodology allows for larger reductions in volatility with each oxidation step than previous volatility basis set models, which is more consistent with the addition of common functional groups and similar to those used by traditional SOA models. The methodology is illustrated using data collected during two field campaigns that characterized the atmospheric evolution of dilute gas-turbine engine emissions using a smog chamber. In those experiments, photo-oxidation formed a significant amount of SOA, much of which could not be explained based on the emissions of traditional speciated precursors; we refer to the unexplained SOA as non-traditional SOA (NT-SOA). The NT-SOA can be explained by emissions of unspeciated low-volatility organics measured using sorbents. We show that the parameterization proposed by Robinson et al. (2007) is unable to explain the timing of the NT-SOA formation in the aircraft experiments because it assumes a very modest reduction in volatility of the precursors with every oxidation reaction. In contrast the new method better reproduces the NT-SOA formation. The NT-SOA yields estimated for the unspeciated low-
\end{abstract}

volatility organic emissions in aircraft exhaust are similar to literature data for large $n$-alkanes and other low-volatility organics. The estimated yields vary with fuel composition (Jet Propellent-8 versus Fischer-Tropsch) and engine load (ground idle versus non-ground idle). The framework developed here is suitable for modeling SOA formation from emissions from other combustion systems.

\section{Introduction}

Atmospheric aerosols exert a large influence on climate and public health (Bernstein et al., 2004; IPCC, 2007). Secondary organic aerosol (SOA), defined as the organic particulate mass arising from the oxidation products of gasphase organic species, accounts for a significant fraction of the submicron dry atmospheric aerosol mass (Zhang et al., 2007). Until recently, SOA formation was believed to be dominated by the first-generation oxidation products of highflux volatile organic compounds (VOC) such as terpenes and single-ring aromatics. SOA formed from speciated VOCs is defined as traditional SOA (T-SOA) and is explicitly accounted for in chemical transport models. However, these models systematically under-predict organic aerosol levels (Heald et al., 2005; Vutukuru et al., 2006; Johnson et al., 2006; Morris et al., 2006; Dzepina et al., 2009, 2010), especially during photo-chemically active periods. 
Recent laboratory and field studies show that combustion emissions when photo-oxidized form substantial SOA mass, greatly in excess of what can be explained by T-SOA models (Robinson et al., 2007; Grieshop et al., 2009; Hodzic et al., 2010; Miracolo et al., 2011, 2012). Robinson et al. (2007) proposed that a significant fraction of the unexplained SOA stemmed from the oxidation of unspeciated low-volatility organics, i.e. semi-volatile and intermediate volatility organic compounds (SVOC and IVOC). SVOCs refer to organic species that have an effective saturation concentration $\left(C^{*}\right)$ between 1 and $10^{3} \mu \mathrm{g} \mathrm{m}^{-3}$ and IVOCs refer to species that have $C^{*}$ values between $10^{4}$ and $10^{7} \mu \mathrm{g} \mathrm{m}^{-3}$. S/IVOCs are co-emitted by combustion sources but are less volatile than VOC. However, these emissions are often not included in models because the vast majority of them cannot be speciated, they do not contribute significantly to ozone formation, and their measurement requires difficult-to-use sorbents. Fundamentally, S/IVOCs form SOA in the same manner as VOCs; gas-phase oxidation adds functional groups to the precursor molecule, creating lower volatility (vapor pressure) products that condense into the particle phase. The lower initial volatility of S/IVOCs mean that they can have higher SOA yields than VOCs (Lim and Ziemann, 2009b; Presto et al., 2010). SOA formed from S/IVOC vapors is denoted as non-traditional SOA (NT-SOA).

A key attribute of S/IVOC vapors is that the vast majority of their mass cannot be speciated by traditional one-dimensional gas-chromatography-based analytical techniques (Schauer et al., 1999, 2002). Instead they are classified as an unresolved complex mixture (UCM) that is thought to be dominated by co-eluting branched and cyclic alkanes (Robinson et al., 2007, 2010; Isaacman et al., 2012; Schauer et al., 1999). The problem is fundamentally caused by the number of isomers growing exponentially with carbon number (Goldstein and Galbally, 2007). Since the molecular identity of the vast majority of S/IVOC mass cannot be ascertained, SOA formation from these compounds cannot be investigated or modeled in the same manner as traditional speciated SOA precursors (benzene, alpha-pinene, et al.). Instead, NT-SOA models have been based on the volatility of the emissions and a volatility-based oxidation mechanism (Robinson et al., 2007; Dzepina et al., 2009; Murphy and Pandis, 2009; Jathar et al., 2011).

Robinson et al. (2007) proposed a method (Robinson2007) for NT-SOA formation in which volatility classified but unspeciated S/IVOC vapors react with the hydroxyl radical $(\mathrm{OH})$ to form products that were one order of magnitude lower in volatility than their precursor. Pye and Seinfeld (2010) proposed a single-step mechanism for unspeciated SVOCs where the products of oxidation were two orders of magnitude lower in volatility than the precursor; they used SOA-yield data for naphthalene as a surrogate for all unspeciated IVOCs. Both methods have been implemented in plume, regional and global chemical transport models and help close large gaps between observed and predicted
SOA concentrations (Shrivastava et al., 2008; Tsimpidi et al., 2010; Dzepina et al., 2010; Pye and Seinfeld, 2010; Jathar et al., 2011) and properties (Jathar et al., 2011; Shrivastava et al., 2008; Dzepina et al., 2009).

There are several shortcomings with existing methods to model NT-SOA formation. First, the methods and their parameters are not based on explicit fitting of experimental data like what is done for traditional SOA. Shrivastava et al. (2008) showed that the parameters used in Robinson et al. (2007) reasonably predict the measured SOA formation from diesel exhaust. Further, the same parameters have been used to model all emissions (fossil fuel, bio fuel and biomass burning) (Shrivastava et al., 2008; Jathar et al., 2011). Pye and Seinfeld (2010) used naphthalene as a surrogate for all unspeciated IVOCs even though these are thought to be mainly branched and cyclic alkanes (Robinson et al., 2007, 2010; Isaacman et al., 2012; Schauer et al., 1999). Second, existing mechanisms assume that each oxidation reaction reduces the volatility of the precursor by one to two orders of magnitude, which is less than the reduction seen with the addition of common functional groups (e.g. acids, nitrates, or carbonyls) (Kroll and Seinfeld, 2008). For VOCs such as benzene ( $\mathrm{Ng}$ et al., 2007), isoprene ( $\mathrm{Ng}$ et al., 2006) and cyclooctane (Tkacik et al., 2012), the particle-phase oxidation products are almost 5 to 8 orders of magnitude lower in volatility than the precursor. Third, the unspeciated IVOC emissions were not directly measured. For the Robinson2007 method they were estimated by scaling POA emissions based on the work of Schauer et al. (1999, 2001, 2002); for the Pye and Seinfeld (2010) method they were estimated by scaling naphthalene emissions.

In this paper, we present a new method (Hybrid method) to represent NT-SOA formation from unspeciated S/IVOC vapors. First, we present the theoretical framework which is based on the volatility basis set approach (Donahue et al., 2006) and the work of Pankow (1994) and Odum et al. (1996). Next, to illustrate the new approach, it is applied to SOA data from smog chamber experiments conducted on dilute aircraft exhaust. A limitation of smog chamber experiments is their limited oxidant exposure; they only capture, at most, the atmospheric evolution of the first generation or two of oxidation of the precursors and their immediate products. Therefore, the data provide little constraint on the potential role of multi-generational oxidation. The Hybrid method is intended to be a general approach to parameterize NT-SOA formation from combustion sources. Here, aircraft exhaust is only used as an illustrative example.

\section{SOA model formulation}

The modeling of both T-SOA and NT-SOA is commonly based on the approach of Pankow (1994) and Odum et al. (1996), which parameterizes smog chamber SOA data using a set of semi-volatile surrogate products. The amount 
of SOA is defined by the gas-particle partitioning of these surrogate products. While Odum et al. (1996) represented SOA with two surrogate products, more recently, researchers (Hildebrandt et al., 2009; Shakya and Griffin, 2010) have used four or more surrogates expressed using the volatility basis set (VBS) (Donahue et al., 2006). The VBS (Donahue et al., 2006) separates low-volatility organics into logarithmically spaced bins of effective saturation concentration $\left(C^{*}\right)$ at 298 K. $C^{*}$ (inverse of the Pankow-type partitioning coefficient, $K_{\mathrm{p}}$ ) is proportional to the saturation vapor pressure; it is a semi-empirical property that describes the gas-particle partitioning of an organic mixture (Pankow, 1994). The gasparticle partitioning of the set of surrogate products is calculated using absorptive partitioning theory:

$\zeta_{i}=\left(1+\frac{C_{i}^{*}}{C_{\mathrm{OA}}}\right)^{-1} \quad C_{\mathrm{OA}}=\sum_{i=1}^{N} \zeta_{i} \times\left. M_{i}\right|_{\mathrm{g}+\mathrm{p}}$

where, $\zeta_{i}$ is the fraction of mass in volatility bin " $i$ " in the particulate phase, $C_{i} *$ is the effective saturation concentration of bin " $i$ " in $\mu \mathrm{g} \mathrm{m}^{-3}, C_{\mathrm{OA}}$ is the total particulate OA concentration in $\mu \mathrm{g} \mathrm{m}^{-3}, M_{i \mid \mathrm{g}+\mathrm{p}}$ is the total organic concentration (gas + particle) in bin " $i$ " in $\mu \mathrm{g} \mathrm{m}^{-3}$ and $N$ is the number of basis set bins. The VBS is used to track the concentration of all low-volatility organics (SOA and S/IVOC emissions). Although both the SOA formation and S/IVOC emissions can be tracked using a single basis set, for this work we use three separate basis sets to separately track different types of material. One VBS tracks the traditional semivolatile products formed from the oxidation of traditional speciated SOA precursors. A second tracks the fresh, un-oxidized S/IVOC emissions and a third tracks the oxidation products from the S/IVOC emissions.

T-SOA has traditionally been modeled using a distribution of first-generation, non-reactive surrogate products that were much lower in volatility than their precursor. More recently, these models have been extended to include multigenerational oxidation of the first-generation products (Lane et al., 2008; Farina et al., 2010; Murphy and Pandis, 2009). Previous work has modeled NT-SOA formation from unspeciated S/IVOCs with a simple, volatility-based multigenerational oxidation scheme (Robinson-2007) (Robinson et al., 2007; Shrivastava et al., 2008; Jathar et al., 2011). However, there are two potential shortcomings with this approach. First, the Robinson-2007 parameterization assumes that each oxidation reaction only reduces the volatility of the precursor by one order of magnitude. However, oxidation reactions form a variety of products with different volatilities; for example the addition of a single carbonyl, alcohol, nitrate or acid group creates a product with a volatility approximately 1, 3, 3 or 4 orders of magnitude lower than the precursor (Kroll and Seinfeld, 2008). Therefore, a more realistic NT-SOA parameterization would distribute the products over a set of volatility bins, with some of the bins having much lower volatility than the precursor species (simi- lar to T-SOA models). Second, the Robinson-2007 parameterization assumes the same reduction in volatility for each generation of oxidation. However, recent experiments indicate that the reduction in volatility due to oxidation reactions changes as the molecules become more oxygenated and fragmentation (carbon-carbon scission) becomes important (Chacon-Madrid et al., 2010; Chacon-Madrid and Donahue, 2011; Kroll et al., 2011). Therefore, a more realistic NT-SOA parameterization would use a different mechanism for later generation oxidation.

To address these shortcomings, we propose that the first generation of NT-SOA production from the oxidation of $\mathrm{S} / \mathrm{IVOC}$ be treated similar to T-SOA (with precursor specific parameters) and that multi-generational oxidation be treated the same for all SOA. We call this the Hybrid approach, which enables a single, unified framework to be used to model both T-SOA and NT-SOA. We first describe that framework and then its application to develop parameterizations for NT-SOA formation.

The framework can be represented using the following equations:

$$
\begin{aligned}
& \frac{\mathrm{d}\left[X_{j}\right]}{\mathrm{d} t}=-k_{\mathrm{Ox}, X_{j}}[\mathrm{Ox}]\left[X_{j}\right] \\
& \frac{\mathrm{d}\left[M_{i \mid \mathrm{g}+\mathrm{p}]}\right.}{\mathrm{d} t}=\underbrace{\sum_{j} \alpha_{i, j} k_{\mathrm{Ox}, X_{j}}[\mathrm{Ox}]\left[X_{j}\right]}_{\text {first-generation products }} \\
&+\underbrace{\sum_{k}^{N} \beta_{i, k} k_{\mathrm{Ox}, M_{k}}[\mathrm{Ox}]\left[M_{k \mid \mathrm{g}}\right]}_{\text {multi-generational oxidation }}-\underbrace{k_{\mathrm{Ox}, M_{i}[\mathrm{Ox}]\left[M_{i \mid \mathrm{g}}\right]}}_{\text {loss }}
\end{aligned}
$$

Equation (2) represents the first-generation oxidation of SOA precursors (speciated VOC or S/IVOC) where $k_{\mathrm{Ox}, X_{j}}$ is the reaction rate between the oxidant $[\mathrm{Ox}]$ and SOA precursor $\left[X_{j}\right]$. The index $j$ indicates different precursors, either speciated VOC precursors or volatility bins of the S/IVOC distribution. Equation (3) tracks the secondary organic material in VBS bin " $i " . M_{i \mid g+p}$ is the total gas + particle organic mass in bin " $i$ " of the VBS; its gas-particle partitioning is calculated using Eq. (1). The first term in Eq. (3) represents the first-generation products formed in bin " $i$ " as a result of the precursor oxidation where $\alpha_{i, j}$ is the mass yield for the firstgeneration oxidation reaction. The second and third terms in Eq. (3) account for the continued evolution of material in the VBS due to multi-generational oxidation where we assume that only vapors in the VBS $\left(\left.M\right|_{\mathrm{g}}\right)$ react. $\beta_{k, i}$ is the mass yield from multi-generational oxidation reactions in bin " $k$ " and $k_{\mathrm{Ox}, \mathrm{M}}$ is the oxidation rate of vapors in the VBS.

To interpret smog chamber data, the framework (Eqs. 13 ) is implemented in a box model that is comprised of two modules: a T-SOA and a NT-SOA module, both of which 
are described below. The T-SOA module is based on a standard SOA model formulated using the VBS (Pankow, 1994; Odum et al., 1996; Donahue et al., 2006); it uses the speciated VOC emissions and oxidant data to predict the amount of T-SOA that is formed. In the NT-SOA module, the amount of NT-SOA formed is first estimated by subtracting off the predicted T-SOA from the measured SOA. Then, the parameters in Eqs. (1-3) are determined by fitting the NT-SOA data.

Defining the NT-SOA by difference effectively assumes that the T-SOA module is correct. However, published yields for T-SOA precursors (e.g. toluene) vary by more than a factor of two (Ng et al., 2007; Lane et al., 2008; Hildebrandt et al., 2009). As discussed below, the T-SOA model used for this work is based on upper end of the published data and therefore the difference approach may systematically underestimate the amount of NT-SOA.

Interpreting smog chamber data with the NT-SOA model (Eqs. 1-3) requires differentiating between first and later generation oxidation products. In the context of this paper, the term "first generation" refers to the first set of stable products that arise after a series of oxidation reactions (Lim and Ziemann, 2005). The term "multi-generation" refers to the continued oxidation of the stable first-generation products. However, cleanly differentiating between the first and later generations of products is difficult in photo-oxidation experiments. In this paper, we empirically differentiate between first and multi-generational oxidation by assuming that the SOA formed during a typical 3 to $4 \mathrm{~h}$ smog chamber experiment is dominated by the first generation of oxidation. This seems like a reasonable assumption because these experiments typically have aggregate hydroxyl radical exposures of around $10^{7}$ molecules $\mathrm{h} \mathrm{cm}^{-3}$, which creates about one efold of oxidation for precursors with typical S/IVOC reaction rate constants (Atkinson and Arey, 2003). This assumption breaks down in systems in which multi-generational products are significantly more reactive than the original precursors.

Based on our definition of first-generation (inside the smog chamber) and multi-generational (beyond the smog chamber) oxidation, theoretically we do not need to run the multigenerational oxidation mechanism while modeling SOA in the smog chamber. But doing so would incorrectly imply that the oxidation products formed in the smog chamber are non-reactive. Hence, for the sake of completeness (but at the cost of not being true to our definitions), we let the oxidation products that are formed in the smog chamber to undergo multi-generational oxidation.

\subsection{Traditional SOA (T-SOA)}

Previously, T-SOA has been defined as the non-reactive, stable oxidation product of traditional SOA precursors. In this work, we define T-SOA as the first and multi-generational SOA mass arising through the oxidation of speciated VOC precursors. To simulate T-SOA formation, $X_{j}$ in Eq. (2) represents an individual precursor (e.g. benzene, toluene, $n$ - dodecane, or cyclohexane) and $\mathrm{OH}$ is assumed to be the only oxidant. We use SAPRC lumping and mass-yields $\left(\alpha_{i, j}\right.$ in Eq. 3) proposed by Murphy and Pandis (2010) for all the speciated VOC precursors listed in Table 2. The Murphy and Pandis (2010) mass yields are at the high end of those reported in the literature; therefore the T-SOA prediction is an upper bound estimate, which, in turn, results in a lower bound estimate for NT-SOA. The lumping and parameters $\left(k_{\mathrm{Ox}, X_{j}}\right.$ and $\left.\alpha_{i, j}\right)$ for the T-SOA model are provided in Tables S1 and S2 (Supplement). Figure 1a shows a schematic for the T-SOA model.

To treat multi-generational oxidation of T-SOA, we use the parameterizations recently applied to anthropogenic SOA in regional and global models (Murphy and Pandis, 2009, 2010; Farina et al., 2010; Jathar et al., 2011). Gas-phase mass of the T-SOA products reacts with the $\mathrm{OH}$ radical $\left(k_{\mathrm{Ox}, \mathrm{M}}=1 \times 10^{-11} \mathrm{~cm}^{3}\right.$ molecules $\left.{ }^{-1} \mathrm{~s}^{-1}\right)$ to form products that are one order of magnitude lower in volatility than the precursor or shifted by one $C^{*}$ bin relative to the precursor. To account for the addition of oxygen, $7.5 \%$ of the precursor's mass is added to the product. Hence, for T-SOA, $\beta_{i, k}$ in Eq. (3) takes the form:

$\beta_{i, k}=\left\{\begin{array}{cc}+1.075 & \text { if } k=i+1 \\ 0 & \text { otherwise }\end{array}\right.$.

\subsection{Non-traditional SOA (NT-SOA)}

NT-SOA is defined as the SOA mass formed through the oxidation of unspeciated S/IVOC vapors. It is calculated experimentally as the difference between the measured SOA and the predicted T-SOA. In this section, we present two different approaches to parameterize the NT-SOA formation using the VBS framework (Eqs. 1-3). The methods differ in whether and how they account for first-generation oxidation and ongoing multi-generational oxidation (see Fig. $1 \mathrm{~b}$ and c).

\subsubsection{Robinson-2007 method}

Robinson et al. (2007) proposed a simple method to model NT-SOA formation, which uses a single oxidation kernel for all S/IVOC oxidation reactions. This method omits a detailed description of the volatility distribution of firstgeneration products and instead uses the same, simple, multi-generational oxidation scheme for every reaction. The method is shown schematically in Fig. $1 b$.

The simplest way to implement this scheme is to place the volatility-resolved unspeciated S/IVOC precursor mass $\left(X_{j}\right)$ directly into the corresponding VBS $\left(M_{i}\right)$, which eliminates Eq. (2) and the first term in Eq. (3). Similar to the treatment of multi-generational oxidation for T-SOA (Lane et al., 2008), any gas-phase mass in the VBS reacts with the $\mathrm{OH}$ radical to form a product that is in a lower volatility bin than its precursor. For NT-SOA (Robinson-2007), $\beta_{i, k}$ takes the form: 

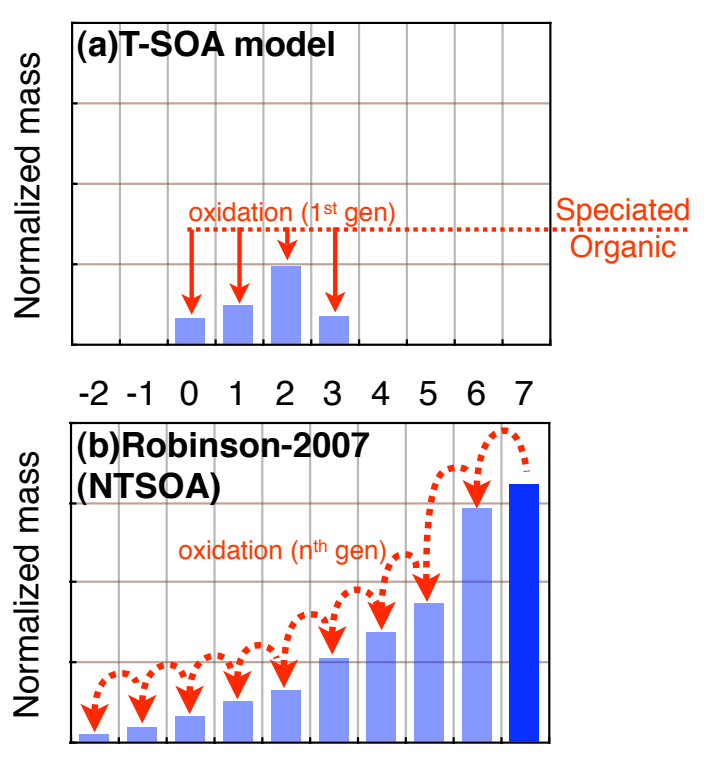

$\begin{array}{llllllllll}-2 & -1 & 0 & 1 & 2 & 3 & 4 & 5 & 6 & 7\end{array}$

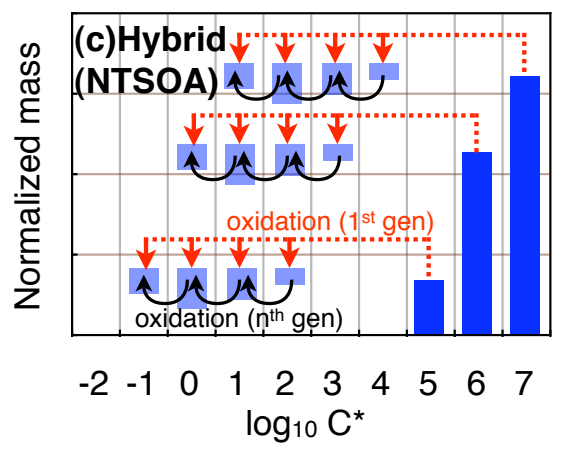

Fig. 1. Schematics that illustrate the SOA mechanism for the (a) T-SOA model, (b) Robinson-2007 method and (c) Hybrid method.

$\beta_{i, k}=\left\{\begin{array}{cl}+\left(1+f_{\text {oxy }}\right) & \text { if } k=i+q \\ 0 & \text { otherwise }\end{array}\right.$

where, $q$ is the shift in volatility for the product and $f_{\text {oxy }}$ is the fraction of oxygen added to the product per reaction.

To simulate NT-SOA formation using the Robinson-2007 method, one must define $k_{\mathrm{Ox}, \mathrm{M}}, f_{\mathrm{oxy}}$ and $q$. Robinson et al. (2007) and Shrivastava et al. (2008) used a $k_{\mathrm{Ox}, \mathrm{M}}$ of $4 \times 10^{-11} \mathrm{~cm}^{3}$ molecules ${ }^{-1} \mathrm{~s}^{-1}$, a $f_{\text {oxy }}$ of 0.075 and a $q$ of 1 based on SOA data for diesel exhaust. Grieshop et al. (2009) proposed a $k_{\mathrm{OH}, \mathrm{M}}$ of $4 \times 10^{-11} \mathrm{~cm}^{3}$ molecules ${ }^{-1} \mathrm{~s}^{-1}$, a $f_{\text {oxy }}$ of 0.40 a $q$ of 2 based on SOA data for dilute woodsmoke. Dzepina et al. $(2009,2010)$ and Hodzic et al. (2010) have applied these parameterizations to simulate SOA formation over Mexico City.

In this manuscript, we evaluate the previously proposed sets of $k_{\mathrm{OH}, \mathrm{M}}, f_{\mathrm{Oxy}}$ and q-values. We also fit the NT-SOA data to determine an optimum set of values for these parameters for the Robinson-2007 method.

\subsubsection{Hybrid method}

The Hybrid method is similar to the previously discussed TSOA model. It is shown schematically in Fig. 1c. The first generation of oxidation of S/IVOC vapors and subsequent NT-SOA formation is parameterized by fitting Eqs. (1-3) to smog chamber data. A generic multi-generational oxidation scheme is then used for subsequent generations of oxidation. This allows for a more physically realistic treatment of the first-generation oxidation that better represents known effects of oxidation on volatility.

In the Hybrid method, for the first generation of oxidation, the volatility-resolved unspeciated S/IVOC emissions are treated as precursors $\left(X_{j}\right)$ in Eq. (2) and their vapors are assumed to react only with the $\mathrm{OH}$ radical. We assume that $k_{\mathrm{Ox}, X_{j}}$ is $4 \times 10^{-11} \mathrm{~cm}^{3}$ molecules ${ }^{-1} \mathrm{~s}^{-1}$ for vapors with a $C^{*}<10^{4} \mu \mathrm{g} \mathrm{m}^{-3}$ and $3 \times 10^{-11} \mathrm{~cm}^{3}$ molecules ${ }^{-1} \mathrm{~s}^{-1}$ for vapors with $C^{*} \geq 10^{4} \mu \mathrm{g} \mathrm{m}^{-3}$ based on reactivity data for $n$ alkanes in these volatility ranges (Atkinson and Arey, 2003).

To determine the mass-yield matrix ( $\alpha_{i, j}$ in Eq. 3 ), we assume that each precursor undergoes several oxidation reactions in the smog chamber before it forms a stable set of products. Hence, we expect the particle-phase oxidation products to be much less volatile compared to its precursor. For a VOC like toluene $\left(C^{*} \sim 1.6 \times 10^{8} \mu \mathrm{g} \mathrm{m}^{-3}\right)$, Hildebrandt et al. (2009) observed that the products of oxidation were centered around the $C^{*}=100$ and $C^{*}=1000 \mu \mathrm{g} \mathrm{m}^{-3}$ bins, i.e. most of the products were 5 to 6 orders of magnitude lower than the precursor (toluene). Tkacik et al. (2012) observed that most of the measurable photo-oxidation products of cycloalkanes and branched alkanes were 3 to 6 orders of magnitude lower in volatility than their precursor. Therefore, we assume that in the Hybrid method, a precursor is allowed to form oxidation products that are 3 to 6 orders of magnitude lower in volatility than the precursor.

The mass-yield matrix ( $\alpha_{i, j}$ in Eq. 3) for the Hybrid method is derived by fitting the NT-SOA data. Since there are eight precursors $\left(C^{*}=1\right.$ to $10^{7} \mu \mathrm{g} \mathrm{m}^{-3}$; Table 2$)$ and each precursor's products are fit across 4 VBS bins, the Hybrid method potentially requires 32 free parameters (many more than can be constrained with the data). Presto et al. (2010), following the work of Lim and Ziemann (2009), found that for $n$-alkanes, the addition of 2 carbon atoms shifted its corresponding SOA product distribution, on average, by one $C^{*}$ bin or one order of magnitude in $C^{*}$ space. Therefore, we assume the same product distribution arising from each S/IVOC precursor bin, but shifted in volatility space by one order of magnitude. This approach reduces the number of free parameters to four. For instance, if $\left[\begin{array}{llll}a_{1} & b_{1} & c_{1} & d_{1}\end{array}\right]$ represents the mass yield for the precursor $C^{*}=10^{6} \mu \mathrm{g} \mathrm{m}^{-3}$ across $C^{*}$ bins [ 1101001000$]\left(\mu \mathrm{g} \mathrm{m}^{-3}\right)$, the mass-yield matrix $\alpha_{i, j}$ for all precursors would take the same form shifted by one bin. 
Table 1. List of smog chamber experiments.

\begin{tabular}{llllll}
\hline No & Experiment Name & Engine & Fuel & Load & Reference \\
\hline 1 & CFM56-JP8-Ground Idle (1) & CFM56-2B & JP8 & $4 \%$ & Presto et al. \\
2 & CFM56-JP8-Ground Idle (2) & CFM56-2B & JP8 & $4 \%$ & (2011, 2012), \\
3 & CFM56-JP8-Ground Idle (3) & CFM56-2B & JP8 & $4 \%$ & Miracolo et \\
4 & CFM56-JP8-Taxi & CFM56-2B & JP8 & $7 \%$ & al. (2011) \\
5 & CFM56-JP8-Landing & CFM56-2B & JP8 & $30 \%$ & \\
6 & CFM56-JP8-Takeoff & CFM56-2B & JP8 & $85 \%$ & \\
\hline 7 & T63-JP8-Ground Idle & T63 & JP8 & Ground Idle & Miracolo et \\
8 & T63-FT-Ground Idle (1) & T63 & FT & Ground Idle & al. (2012), \\
9 & T63-FT-Ground Idle (2) & T63 & FT & Ground Idle & Drozd et al. (2012), \\
10 & T63-Blend-Ground Idle & T63 & JP8:FT Blend & Ground Idle & Presto et al. (2012) \\
11 & T63-JP8-Cruise & T63 & JP8 & Cruise & \\
12 & T63-FT-Cruise & T63 & FT & Cruise &
\end{tabular}

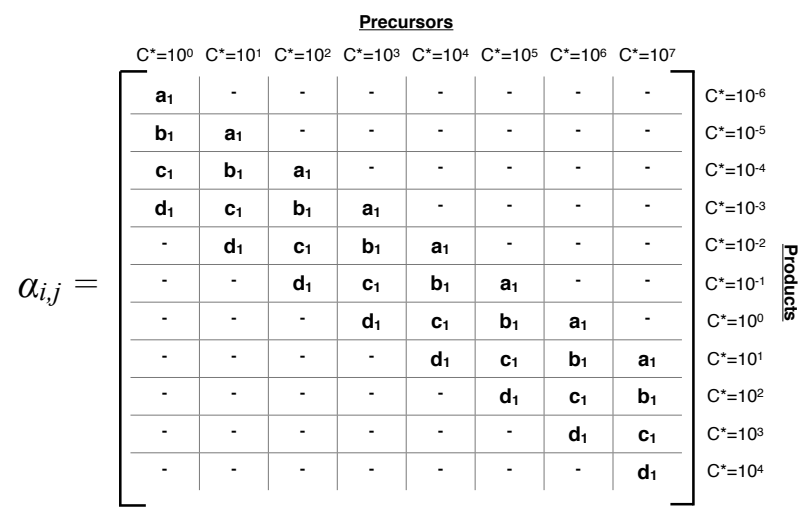

(6)

For multi-generational oxidation, we use the same set of parameters used to model the multi-generational oxidation of T-SOA (Eq. 4).

\section{Experimental data}

\subsection{Overview of experimental methods}

The Hybrid model is illustrated using data from smog chamber experiments conducted on diluted emissions from two different gas-turbine aircraft engines. Here, we provide a brief overview of both datasets; further details can be found in Miracolo et al. (2011), Presto et al. (2011), Miracolo et al. (2012) and Drozd et al. (2012). The first study investigated SOA formation from diluted emissions from a CFM56-2B gas-turbine engine operating on Jet Propellant - 8 (JP8) fuel (Presto et al., 2011; Miracolo et al., 2011) at four different engine loads (4\% - ground idle, $7 \%$ - taxiing, $30 \%$ - landing and $85 \%$ - takeoff). In the second study, experiments were conducted on diluted emissions from a T63 gas turboshaft engine operating on JP8, Fischer-Tropsch (FT) and
JP8/FT 50:50 blend fuels at ground idle and cruise loads. On a mass-basis, JP8 consists of $53 \%$ straight/cyclic alkanes, $30 \%$ branched alkanes and $17 \%$ aromatics while FT consists of $88 \%$ branched alkanes and $12 \%$ cyclic alkanes (Corporan et al., 2011). The experiments used in this work are listed in Table 1, including the naming convention used in the paper.

Briefly, the experiments involved collecting emissions from about 1-m downstream of the engine exit plane and then transferring them through a heated transfer line into a portable Teflon smog chamber. The emissions were diluted 50 to 200 times with clean (HEPA- and activated-carbon filter) air to achieve primary PM concentration levels in the chamber that were representative of those typically found roughly $100-\mathrm{m}$ downstream of the engine exit plane $(<10$ $\left.\mu \mathrm{g} \mathrm{m}^{-3}\right)$. To initiate photo-oxidation, the chamber was exposed to natural or artificial sunlight; a suite of instruments tracked the evolution of the gas- and particle-phase pollutants. Photo-oxidation increased the aerosol levels inside the chamber, in certain experiments to $100 \mathrm{~s}$ of $\mu \mathrm{g} \mathrm{m}^{-3}$. The relative humidity in the chamber was low $(<18 \%)$.

\subsection{Overview of PM and SOA data}

Figure 2 compiles the primary (elemental carbon and primary organic aerosol or POA) and secondary PM (sulfate and SOA) data from the two field campaigns. Briefly, EC and POA emissions were based on quartz filter samples collected off of a dilution tunnel (Drozd et al., 2012; Presto et al., 2011). Sulfate and SOA were based on AMS and SMPS measurements made at the end of $\sim 3$ to $4 \mathrm{~h}$ of photooxidation inside the smog chamber (Miracolo et al., 2011, 2012). The chamber data were converted to a fuel basis using the background-corrected measured $\mathrm{CO}_{2}$ concentration. The sum of the measured primary PM emissions and secondary PM formation spans two orders of magnitude (50-4250 mg $\mathrm{kg}$-fuel ${ }^{-1}$ ) and is a strong function of the engine type, engine load and fuel. These variations are discussed in detail in companion publications (Presto et al., 2011; Miracolo et 
Table 2. Emission factor (mg kg-fuel ${ }^{-1}$ ) for speciated VOCs and S/IVOCs for each engine, fuel and engine load (Miracolo et al., 2011, 2012; Presto et al., 2012). $C^{*}$ values are determined either from the NIST database or EPA's Estimation Program Interface suite.

\begin{tabular}{|c|c|c|c|c|c|c|c|c|c|c|c|}
\hline \multirow[t]{2}{*}{ Type } & \multirow[t]{2}{*}{ Species } & \multirow[t]{2}{*}{$C^{*}(\mu \mathrm{g} \mathrm{m}-3)$} & \multicolumn{4}{|c|}{ CFM56-JP8 } & \multicolumn{2}{|c|}{ T63-JP8 } & \multicolumn{2}{|c|}{ T63-FT } & \multirow{2}{*}{$\begin{array}{c}\text { T63-Blend } \\
\text { Ground Idle }\end{array}$} \\
\hline & & & Ground Idle & Taxi & Landing & Takeoff & Ground Idle & Cruise & Ground Idle & Cruise & \\
\hline \multirow[t]{63}{*}{ VOC } & 1-butene & $6.42 \times 10^{9}$ & 194.6 & 58.4 & 2.2 & 2.2 & 401.1 & 1.2 & 159.1 & 1.5 & 292.7 \\
\hline & 1-heptene & $3.21 \times 10^{8}$ & 61.5 & 18.5 & - & - & 0.1 & 0.0 & 6.3 & 0.0 & 11.6 \\
\hline & 1-hexene & $8.35 \times 10^{8}$ & 81.1 & 24.3 & - & - & - & - & - & - & - \\
\hline & 1-methylcyclohexene & $3.90 \times 10^{8}$ & 5.2 & 1.6 & - & - & - & - & - & - & - \\
\hline & 1-octene & $1.04 \times 10^{8}$ & 5.9 & 1.8 & 1.2 & 1.2 & - & - & - & - & - \\
\hline & 1-pentene & $2.39 \times 10^{9}$ & 91.2 & 27.4 & 10.8 & 10.8 & 81.7 & 0.0 & 69.8 & 0.0 & 0.0 \\
\hline & 1,2-butadiene & $2.71 \times 10^{9}$ & 6.4 & 1.9 & - & - & 1.4 & 0.0 & 4.8 & 0.0 & 3.7 \\
\hline & 1,2-diethylbenzene & $7.04 \times 10^{6}$ & 10.9 & 3.3 & 1.9 & 1.9 & - & - & - & - & - \\
\hline & 1,2,3-trimethylbenzene & $9.51 \times 10^{6}$ & 47.0 & 14.1 & 1.7 & 1.7 & 4.3 & 0.0 & 10.8 & 0.0 & 32.7 \\
\hline & 1,2,4-trimethylbenzene & $1.30 \times 10^{7}$ & 41.9 & 12.6 & 7.4 & 7.4 & 24.9 & 0.0 & 30.5 & 0.0 & 119.8 \\
\hline & 1,2,4,5-tetramethylbenzene & $1.12 \times 10^{6}$ & 27.2 & 8.2 & - & - & - & - & - & - & - \\
\hline & 1,3-butadiene & $6.11 \times 10^{9}$ & 230.3 & 69.1 & - & - & 391.3 & 2.8 & 76.4 & 1.4 & 0.0 \\
\hline & 1,3-diethylbenzene & $7.67 \times 10^{6}$ & 10.2 & 3.1 & 1.8 & 1.8 & 14.6 & 1.2 & 180.9 & 0.0 & 125.4 \\
\hline & 1,3,5-trimethylbenzene & $1.54 \times 10^{7}$ & 14.4 & 4.3 & 1.0 & 1.0 & 16.4 & 0.0 & 39.1 & 0.0 & 47.7 \\
\hline & 1,4-diethylbenzene & $7.13 \times 10^{6}$ & 46.7 & 14.0 & 1.9 & 1.9 & 3.7 & 3.9 & 75.6 & 0.0 & 68.2 \\
\hline & 2-ethyltoluene & $1.59 \times 10^{7}$ & 12.6 & 3.8 & 34.2 & 34.2 & 16.0 & 2.8 & 11.1 & 0.0 & 30.7 \\
\hline & 2-methyl-1-butene & $2.29 \times 10^{9}$ & 30.3 & 9.1 & 1.0 & 1.0 & 52.5 & 0.0 & 81.1 & 0.0 & 26.6 \\
\hline & 2-methyl-1-pentene & $1.25 \times 10^{9}$ & 10.6 & 3.2 & - & - & 5.2 & 0.0 & 10.7 & 0.0 & 4.1 \\
\hline & 2-methyl-2-butene & $1.75 \times 10^{9}$ & 6.0 & 1.8 & - & - & 9.6 & 0.0 & 21.7 & 0.0 & 24.1 \\
\hline & 2-methyl-2-pentene & $1.25 \times 10^{9}$ & 2.1 & 0.6 & 0.6 & 0.6 & - & - & - & - & - \\
\hline & 2-methylheptane & $1.26 \times 10^{8}$ & 7.1 & 2.1 & - & - & 8.9 & 0.0 & 5.6 & 0.0 & 8.6 \\
\hline & 2-methylhexane & $3.52 \times 10^{8}$ & 6.7 & 2.0 & - & - & 30.2 & 0.0 & 8.5 & 0.0 & 20.2 \\
\hline & 2-methylpentane & $9.74 \times 10^{8}$ & 50.2 & 15.1 & 1.0 & 1.0 & - & 2.1 & 11.5 & 0.0 & 17.0 \\
\hline & 2,2-dimethylbutane & $1.46 \times 10^{9}$ & 1.5 & 0.5 & - & - & 64.8 & 0.0 & 19.8 & 0.0 & 0.0 \\
\hline & 2,3-dimethyl-2-pentene & $2.40 \times 10^{8}$ & 7.5 & 2.3 & 1.0 & 1.0 & 14.7 & 0.0 & 5.2 & 0.0 & 14.4 \\
\hline & 2,3-dimethylbutane & $1.08 \times 10^{9}$ & 2.8 & 0.8 & 2.0 & 2.0 & 54.1 & 4.5 & 16.1 & 0.0 & 58.9 \\
\hline & 2,3,4-trimethylpentane & $1.64 \times 10^{8}$ & 5.3 & 1.6 & - & - & 8.5 & 0.0 & 27.8 & 0.0 & 23.8 \\
\hline & 2,4-dimethylpentane & $3.52 \times 10^{8}$ & _- & - & - & - & 2.6 & 0.0 & 19.2 & 0.0 & 18.9 \\
\hline & 3-ethyltoluene & $1.87 \times 10^{7}$ & 15.8 & 4.7 & - & - & 9.1 & 0.5 & 34.4 & 0.0 & 18.9 \\
\hline & 3-methyl-1-butene & $2.29 \times 10^{9}$ & 29.5 & 8.9 & - & - & - & - & - & - & - \\
\hline & 3-methylheptane & $1.20 \times 10^{8}$ & 5.7 & 1.7 & 2.9 & 2.9 & - & 0.8 & 6.0 & 0.0 & 4.3 \\
\hline & 3-methylhexane & $3.29 \times 10^{8}$ & 24.5 & 7.4 & - & - & 2.6 & 0.9 & 9.6 & 0.0 & 15.7 \\
\hline & 3-methylpentane & $8.73 \times 10^{8}$ & 12.5 & 3.8 & - & - & 4.7 & 0.0 & 7.4 & 0.0 & 23.7 \\
\hline & 4-ethyltoluene & $1.89 \times 10^{7}$ & 7.7 & 2.3 & 3.1 & 3.1 & 27.2 & 0.0 & 66.1 & 0.0 & 65.9 \\
\hline & 4-methyl-1-pentene & $1.25 \times 10^{9}$ & 27.2 & 8.2 & 0.7 & 0.7 & - & - & - & - & - \\
\hline & 4-methylheptane & $1.25 \times 10^{8}$ & 5.6 & 1.7 & 1.8 & 1.8 & - & 0.0 & 9.4 & 0.0 & 6.9 \\
\hline & alpha-pinene & $3.47 \times 10^{7}$ & 6.2 & 1.9 & - & - & 17.4 & 0.9 & 87.9 & 0.0 & 60.7 \\
\hline & acetylene & $5.05 \times 10^{10}$ & 2858.9 & 857.7 & 9.2 & 9.2 & 861.8 & 37.4 & 859.9 & 12.0 & 834.1 \\
\hline & benzene & $4.61 \times 10^{8}$ & 232.0 & 69.6 & 72.4 & 72.4 & 282.1 & 4.8 & 126.3 & 0.8 & 217.8 \\
\hline & butane & $6.18 \times 10^{9}$ & 24.8 & 7.4 & 29.2 & 29.2 & 40.2 & 0.0 & 258.0 & 1.5 & 282.4 \\
\hline & butylbenzene & $7.35 \times 10^{6}$ & 8.5 & 2.6 & - & - & 5.2 & 0.5 & 111.3 & 0.0 & 13.1 \\
\hline & c-1,3-dimethylcyclopentane & $3.52 \times 10^{8}$ & - & - & - & - & 0.7 & 0.0 & 12.1 & 0.0 & 2.2 \\
\hline & c-2-butene & $3.50 \times 10^{9}$ & 11.7 & 3.5 & 0.9 & 0.9 & 15.2 & 0.6 & 87.6 & 1.1 & 60.9 \\
\hline & c-2-hexene & $1.25 \times 10^{9}$ & 6.1 & 1.8 & 14.4 & 14.4 & 18.3 & 0.0 & 17.3 & 0.0 & 28.3 \\
\hline & c-2-pentene & $2.29 \times 10^{9}$ & 8.4 & 2.5 & - & - & 61.5 & 0.0 & 68.2 & 0.0 & 34.9 \\
\hline & c-3-hexene & $1.25 \times 10^{9}$ & 7.2 & 2.2 & - & - & - & - & - & - & - \\
\hline & cyclohexane & $4.32 \times 10^{8}$ & 51.9 & 15.6 & - & - & 1.5 & 0.0 & 58.7 & 0.0 & 3.6 \\
\hline & cyclohexene & $3.87 \times 10^{8}$ & 14.5 & 4.4 & 3.7 & 3.7 & 4.5 & 0.0 & 4.4 & 0.0 & 14.0 \\
\hline & cyclopentane & $1.19 \times 10^{9}$ & 12.6 & 3.8 & 1.8 & 1.8 & 27.3 & 0.0 & 34.7 & 0.0 & 14.6 \\
\hline & cyclopentene & $3.56 \times 10^{8}$ & 95.5 & 28.7 & - & - & 2.0 & 0.0 & 23.9 & 0.0 & 12.4 \\
\hline & cyclopropane & $1.23 \times 10^{10}$ & 2.9 & 0.9 & - & - & - & - & - & - & - \\
\hline & decane & $8.42 \times 10^{6}$ & 2.5 & 0.8 & 33.4 & 33.4 & 5.5 & 9.4 & 177.6 & 0.0 & 178.5 \\
\hline & dodecane & $1.04 \times 10^{6}$ & 108.3 & 32.5 & 16.1 & 16.1 & - & - & - & - & - \\
\hline & ethane & $6.13 \times 10^{10}$ & 115.5 & 34.7 & 83.3 & 83.3 & 154.4 & 27.4 & 147.3 & 0.0 & 122.3 \\
\hline & ethene & $5.90 \times 10^{10}$ & 77.3 & 23.2 & 28.1 & 28.1 & 2958.1 & 51.2 & 1414.3 & 9.6 & 2302.9 \\
\hline & ethylbenzene & $6.28 \times 10^{7}$ & 3.9 & 1.2 & 1.0 & 1.0 & 24.9 & 0.0 & 60.7 & 0.0 & 58.1 \\
\hline & heptane & $2.43 \times 10^{8}$ & 5.9 & 1.8 & - & - & 137.1 & 0.0 & 16.7 & 0.0 & 87.9 \\
\hline & hexane & $6.10 \times 10^{8}$ & 15.4 & 4.6 & 2.4 & 2.4 & 239.4 & 69.1 & 27.6 & 0.0 & 115.7 \\
\hline & hexylbenzene & $1.00 \times 10^{7}$ & 16.6 & 5.0 & - & - & - & - & - & - & - \\
\hline & i-butane & $8.15 \times 10^{9}$ & 42.7 & 12.8 & 42.2 & 42.2 & 5.0 & 0.4 & 91.0 & 0.0 & 0.0 \\
\hline & i-butene & $3.47 \times 10^{9}$ & 71.7 & 21.5 & 5.5 & 5.5 & 123.7 & 0.0 & 525.4 & 0.0 & 328.2 \\
\hline & i-pentane & $1.38 \times 10^{9}$ & 34.0 & 10.2 & 29.9 & 29.9 & 0.0 & 0.0 & 0.0 & 0.0 & 208.9 \\
\hline & isoprene & $1.05 \times 10^{9}$ & 56.0 & 16.8 & - & - & 84.9 & 0.0 & 39.6 & 0.0 & 3.9 \\
\hline
\end{tabular}


Table 2. Continued.

\begin{tabular}{|c|c|c|c|c|c|c|c|c|c|c|c|}
\hline \multirow[t]{2}{*}{ Type } & \multirow[t]{2}{*}{ Species } & \multirow[t]{2}{*}{$C^{*}(\mu \mathrm{g} \mathrm{m}-3)$} & \multicolumn{4}{|c|}{ CFM56-JP8 } & \multicolumn{2}{|c|}{ T63-JP8 } & \multicolumn{2}{|c|}{ T63-FT } & \multirow{2}{*}{$\begin{array}{c}\text { T63-Blend } \\
\text { Ground Idle }\end{array}$} \\
\hline & & & Ground Idle & Taxi & Landing & Takeoff & Ground Idle & Cruise & Ground Idle & Cruise & \\
\hline & i-propylbenzene & $2.92 \times 10^{7}$ & 4.8 & 1.4 & 0.8 & 0.8 & 8.6 & 0.0 & 105.2 & 0.0 & 69.9 \\
\hline & limonene & $1.05 \times 10^{7}$ & 7.9 & 2.4 & - & - & 0.0 & 0.0 & 0.0 & 0.0 & 0.0 \\
\hline & m-xylene & $4.70 \times 10^{7}$ & 26.4 & 7.9 & 1.1 & 1.1 & 38.8 & 0.0 & 56.9 & 0.0 & 5.6 \\
\hline & methylcyclohexane & $5.00 \times 10^{8}$ & 14.4 & 4.3 & - & - & 5.2 & 0.0 & 5.9 & 0.0 & 12.3 \\
\hline & methylcyclopentane & $6.17 \times 10^{8}$ & 11.2 & 3.4 & - & - & 2.7 & 0.0 & 12.1 & 0.0 & 11.0 \\
\hline & naphthalene & $1.52 \times 10^{6}$ & 45.9 & 13.8 & 1.6 & 1.6 & - & - & - & - & - \\
\hline & nonane & $2.63 \times 10^{7}$ & 36.1 & 10.8 & - & - & 116.1 & 0.0 & 3.5 & 0.0 & 93.6 \\
\hline & o-xylene & $3.74 \times 10^{7}$ & 5.2 & 1.6 & - & - & 24.8 & 0.0 & 68.1 & 0.0 & 62.4 \\
\hline & octane & $8.18 \times 10^{7}$ & 7.5 & 2.3 & 0.9 & 0.9 & 15.4 & 0.0 & 3.5 & 0.0 & 16.7 \\
\hline & p-xylene & $5.65 \times 10^{7}$ & 4.8 & 1.4 & 3.8 & 3.8 & 20.3 & 1.0 & 45.6 & 0.0 & 73.9 \\
\hline & pentane & $1.97 \times 10^{9}$ & 12.0 & 3.6 & 15.6 & 15.6 & 12.7 & 0.0 & 62.2 & 0.0 & 3.5 \\
\hline & propane & $1.70 \times 10^{10}$ & 37.4 & 11.2 & 32.6 & 32.6 & 31.3 & 0.0 & 15.8 & 0.0 & 10.7 \\
\hline & propene & $1.95 \times 10^{10}$ & 696.2 & 208.9 & 6.3 & 6.3 & 1123.0 & 5.4 & 1149.0 & 14.3 & 1192.6 \\
\hline & propylbenzene & $2.16 \times 10^{7}$ & 16.6 & 5.0 & 1.4 & 1.4 & 15.1 & 0.0 & 36.2 & 0.0 & 29.6 \\
\hline & propyne & $5.04 \times 10^{9}$ & 72.3 & 21.7 & - & - & 86.7 & 0.8 & 100.1 & 0.1 & 95.2 \\
\hline & sec-butylbenzene & $1.29 \times 10^{7}$ & 39.4 & 11.8 & 1.6 & 1.6 & - & - & - & - & - \\
\hline & styrene & $3.51 \times 10^{7}$ & 8.2 & 2.5 & - & - & 12.8 & 0.0 & 7.7 & 0.0 & 18.7 \\
\hline & tetradecane & $9.94 \times 10^{4}$ & 4.9 & 1.5 & 0.9 & 0.9 & - & - & - & - & - \\
\hline & toluene & $1.58 \times 10^{8}$ & 84.7 & 25.4 & 3.0 & 3.0 & 112.0 & 1.6 & 34.8 & 0.3 & 76.1 \\
\hline & 1,3-hexadiene (trans) & $1.25 \times 10^{9}$ & 6.3 & 1.9 & - & - & 7.8 & 0.0 & 30.5 & 0.0 & 7.0 \\
\hline & $\mathrm{t}$-2-butene & $2.75 \times 10^{9}$ & 61.0 & 18.3 & 4.3 & 4.3 & 54.7 & 1.1 & 119.8 & 0.4 & 83.5 \\
\hline & $\mathrm{t}$-2-hexene & $1.25 \times 10^{9}$ & 9.5 & 2.9 & - & - & 10.2 & 0.0 & 13.4 & 0.0 & 10.4 \\
\hline & $\mathrm{t}$-2-pentene & $2.29 \times 10^{9}$ & 15.7 & 4.7 & - & - & 105.4 & 0.0 & 28.8 & 0.0 & 106.8 \\
\hline & tridecane & $3.29 \times 10^{5}$ & 47.4 & 14.2 & 1.9 & 1.9 & - & - & - & - & - \\
\hline & undecane & $3.26 \times 10^{6}$ & 93.7 & 28.1 & 15.8 & 15.8 & 2.3 & 2.6 & 46.6 & 0.0 & 76.5 \\
\hline \multirow[t]{4}{*}{ SVOC } & $C^{*}=10^{0} \mu \mathrm{g} \mathrm{m}^{-3}$ & $1.00 \times 10^{0}$ & 6.4 & 3.4 & 4.7 & 3.8 & 24.7 & 0.2 & 28.7 & 7.7 & 18.7 \\
\hline & $C^{*}=10^{1} \mu \mathrm{g} \mathrm{m}^{-3}$ & $1.00 \times 10$ & 4.8 & 10.6 & 7.0 & 4.5 & 61.8 & 0.6 & 76.6 & 14.0 & 56.4 \\
\hline & $C^{*}=10^{2} \mu \mathrm{g} \mathrm{m}^{-3}$ & $1.00 \times 10^{2}$ & 4.8 & 23.5 & 7.0 & 4.9 & 85.5 & 0.8 & 118.8 & 3.1 & 73.6 \\
\hline & $C^{*}=10^{3} \mu \mathrm{g} \mathrm{m}^{-3}$ & $1.00 \times 10^{3}$ & 11.2 & 158.8 & 16.4 & 13.4 & 15.0 & 0.1 & 1.8 & 0.0 & 8.0 \\
\hline \multirow[t]{4}{*}{ IVOC } & $C^{*}=10^{4} \mu \mathrm{g} \mathrm{m}^{-3}$ & $1.00 \times 10^{4}$ & 25.6 & 285.1 & 10.4 & 8.4 & 56.2 & 0.5 & 9.7 & 0.0 & 26.6 \\
\hline & $C^{*}=10^{5} \mu \mathrm{g} \mathrm{m}^{-3}$ & $1.00 \times 10^{5}$ & 80.0 & 34.1 & 4.0 & 5.9 & 984.0 & 9.4 & 196.3 & 12.6 & 493.3 \\
\hline & $C^{*}=10^{6} \mu \mathrm{g} \mathrm{m}^{-3}$ & $1.00 \times 10^{6}$ & 1459.4 & 39.1 & 20.0 & 11.3 & 4901.3 & 46.6 & 3613.6 & 12.4 & 3814.1 \\
\hline & 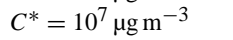 & $1.00 \times 10^{7}$ & 1459.4 & 39.1 & 20.0 & 11.3 & 4901.3 & 46.6 & 3613.6 & 12.4 & 3814.1 \\
\hline
\end{tabular}

al., 2011, 2012; Presto et al., 2012; Drozd et al., 2012); here the focus is on modeling the SOA formation measured in the smog chamber. Briefly, at the end of every experiment, the wall-loss corrected secondary PM formation exceeded the direct primary PM emissions, by as much as a factor of 75 . SOA accounts for more than half of the secondary PM mass (remainder is sulfate) except for in the CFM56-JP8-Takeoff and T63-FT-Cruise experiments and more than three quarters of the PM mass in the ground-idle experiments. On average, the T63 engine had higher emissions and higher secondary PM formation than the CFM56 engine. Both the SOA formation and precursor emissions decrease substantially with increasing engine load, i.e. ground idle vs. takeoff and ground idle vs. cruise.

\subsection{Measured SOA precursors}

Simulating SOA formation requires detailed information on SOA precursor concentrations. Table 2 reports VOC and S/IVOC emissions data for the different experiments. The VOC data were measured using SUMMA canisters that were analyzed using a GC-MS (Presto et al., 2011). VOC measure- ments were only made for one of three CFM56-JP8-Ground Idle experiments; therefore, we assumed that the same VOC emissions profile applies to the other two experiments. For the CFM56-JP8-Taxi and CFM56-JP8-Landing experiments, only a small number of VOC were measured (Presto et al., 2011) and therefore we estimated emissions of additional VOC using data from the APEX study (Wey et al., 2006). The VOC emissions at taxi were assumed to be $40 \%$ of those at ground idle and VOC emissions at landing were assumed to be the same as those at takeoff.

S/IVOC emissions were characterized by GC-MS analysis of quartz filter and Tenax TA sorbent tube samples (Presto et al., 2011). Formally, we define S/IVOC as the sum of (both speciated and unspeciated) emissions that have a $C^{*}$ lower than or equal to $10^{7} \mu \mathrm{g} \mathrm{m}^{-3}$. Presto et al. (2011) speciated less than $10 \%$ of the S/IVOC emissions (similar to studies done with other sources, Schauer et al., 1999, 2002); the remainder was reported as an unresolved complex mixture. To estimate the total mass of S/IVOC emissions, Presto et al. (2012) developed a calibration curve for the UCM mass with fuel and lubricating oil used by the aircraft. The emissions were then distributed into the VBS based on the GC 


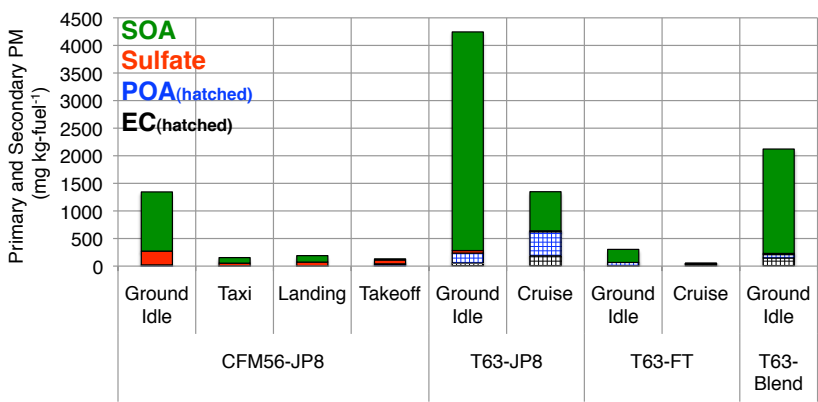

Fig. 2. Average of the measured elemental carbon and POA emissions and sulfate and SOA formation from aircraft exhaust (Miracolo et al., 2011, 2012). CFM56 and T63 are gas turbine engines. JP8 is a petroleum-based aviation fuel, FT is a Fischer-Tropsch fuel derived from coal and Blend is a 50:50 JP8:FT mixture. The results for CFM56-JP8-Ground Idle are the average of three separate experiments and the results for T63-FT-Ground Idle are the average of two separate experiments. We did not perform a cruise experiment for T63-Blend.

elution time (Presto et al., 2012). Further, they found that the chromatogram for all ground-idle emissions appeared to peak near a $C^{*}$ of $10^{6} \mu \mathrm{g} \mathrm{m}^{-3}$ implying that there were considerable emissions of species with a $C^{*}$ greater than $10^{6} \mathrm{\mu g} \mathrm{m}^{-3}$ that could not be quantified but likely also contributed to SOA formation. To ensure the inclusion of all low volatility organics that are capable of forming SOA, we assume that the mass of emissions in the $C^{*}=10^{7} \mu \mathrm{g} \mathrm{m}^{-3}$ bin equals the mass in the $C^{*}=10^{6} \mu \mathrm{g} \mathrm{m}^{-3}$ bin for all the ground-idle experiments. Table 2 reports measured S/IVOC emissions as a function of $C^{*}$.

Figure 3 plots the measured SOA and its precursors S/IVOC and VOC - for the different experiments. The bar labeled VOCs in Fig. 3 only includes SOA precursors based on the SAPRC classification. Apart from the T63-JP8-Cruise experiment, the measured SOA mass is smaller than the sum of the precursor (S/IVOC + VOC) emissions. The precursor mass should be larger than the SOA mass if the SOA is formed from gas-phase oxidation of organic vapors. The VOC data were of poor quality in the cruise experiments. We hypothesize that these precursors may be mostly oxygenated and therefore poorly detected by the hydrocarbon-focused techniques employed by Presto et al. (2012). The S/IVOC emissions, on average, are larger than the speciated SOA precursors and therefore likely to be very important SOA precursors. Most of the S/IVOC emissions are IVOC.

\subsection{Oxidant concentrations}

The vast majority of the SOA precursors in aircraft exhaust are saturated species (there are significant unsaturated light VOCs, which do not form SOA); therefore the SOA formation in the smog chamber experiments is largely driven by oxidation by the hydroxyl radical $(\mathrm{OH})$ and not by ozone. $\mathrm{OH}$

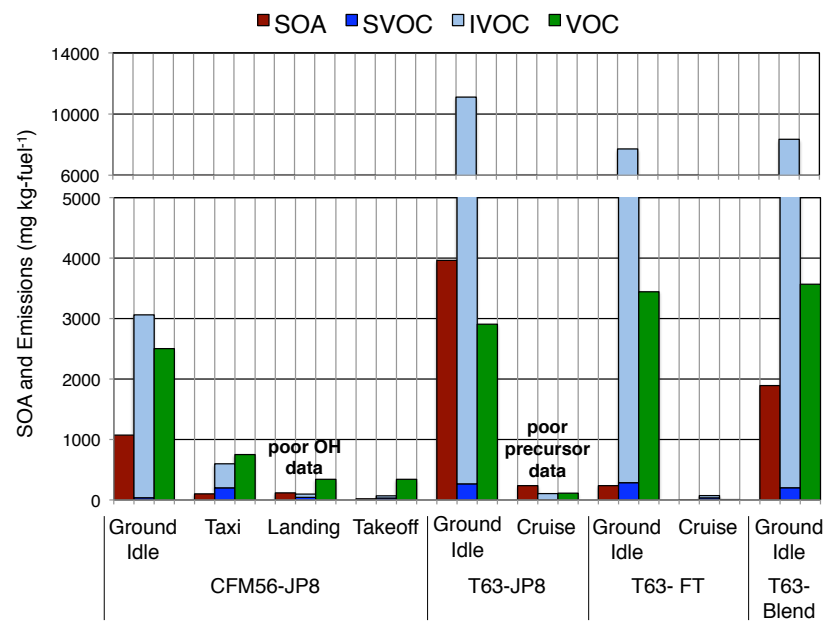

Fig. 3. Emission factors for S/IVOC and VOC (SOA precursors) and measured SOA production. The results for CFM56-JP8-Ground Idle are the average of three separate experiments and the results for T63-FT-Ground Idle are the average of two separate experiments. We did not perform a cruise experiment for T63-Blend.

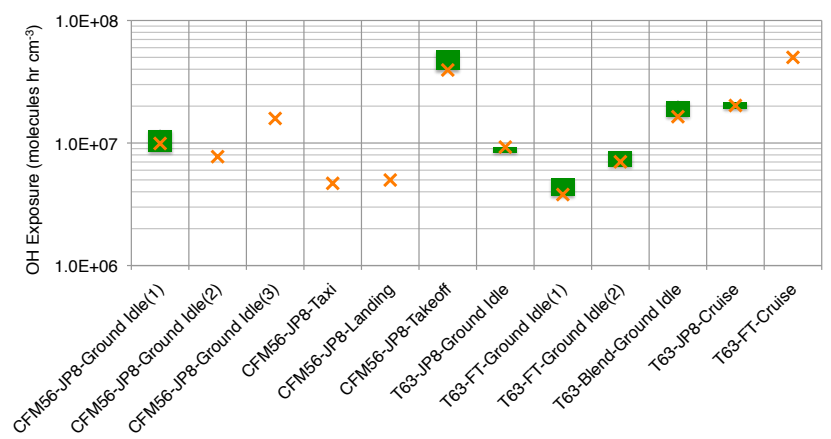

Fig. 4. Estimated $\mathrm{OH}$ exposure range $\left(\right.$ molecules $\mathrm{h} \mathrm{cm}^{-3}$ ) for the twelve different experiments. The median $\mathrm{OH}$ exposure is shown by the orange cross and the standard error of the mean is shown using green bars. We use the median value in our analysis.

concentrations were not directly measured but inferred from the measured decay of organic (e.g. toluene) and inorganic (e.g. $\mathrm{SO}_{2}$ ) species. The $\mathrm{OH}$ concentration varied with time; it was about $10^{7}$ molecules $\mathrm{cm}^{-3}$ at the beginning of the experiment and dropped to $10^{6}$ molecules $\mathrm{cm}^{-3}$ by the end. This time variation was accounted for in the modeling. For some experiments, we estimated the $\mathrm{OH}$ exposure only using high reactivity species $\left(k_{\mathrm{OH}}>10^{-11} \mathrm{~cm}^{3}\right.$ molecules $\left.{ }^{-1} \mathrm{~s}^{-1}\right)$ to reduce uncertainties associated with any chamber leakage. Figure 4 shows the median $\mathrm{OH}$ exposure (orange cross) with the standard error of the mean (green bars) calculated for each experiment. The $\mathrm{OH}$ exposure ranges from 4 to almost $50 \mathrm{~h}$ of atmospheric oxidation at a typical $\mathrm{OH}$ concentration of $10^{6}$ molecules $\mathrm{cm}^{-3}$. 
(a) T-SOA only

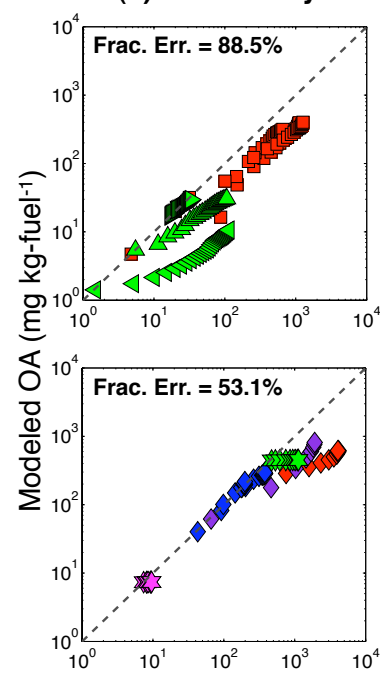

(b) T-SOA + NT-SOA (Robinson-2007)
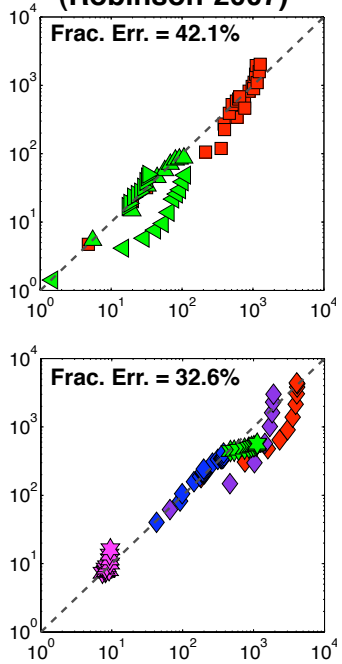

Measured OA (mg kg-fuel-1) (c) T-SOA + NT-SOA

(Hybrid)
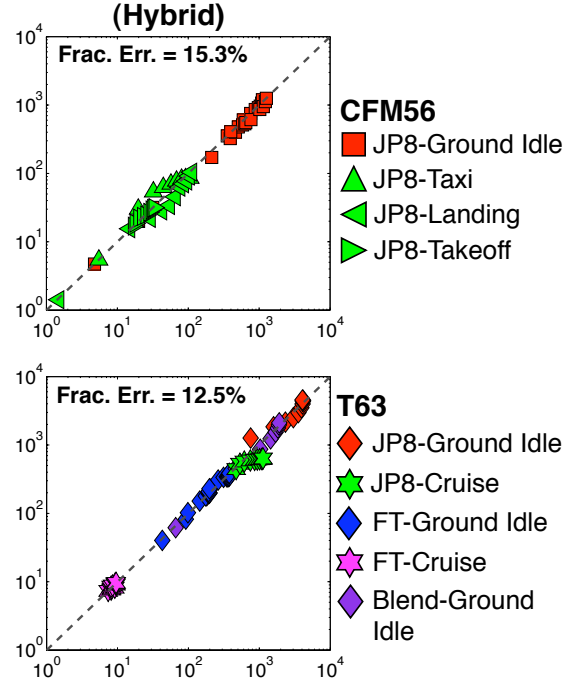

Fig. 5. Scatter plots of predicted versus measured OA mass for the T-SOA model and two versions of the NT-SOA model (Robinson-2007 and Hybrid). The top row shows experiments performed with the CFM56 engine and the bottom row shows experiments performed with the T63 engine.

\section{Results}

\subsection{T-SOA}

Model predictions for the T-SOA module are evaluated in Fig. 5a. Each point represents a time-averaged value over $\sim 100$ s from an individual experiment. The CFM56 and T63 data are presented in separate panels. The model predicts that aromatics are the most important T-SOA precursors. In order to quantify the model-measurement comparison, we calculate the fractional error:

Fractional Error $=\frac{1}{N} \sum_{i=1}^{N} \frac{|P-M|}{\frac{P+M}{2}}$

where $P$ is the predicted OA, $M$ is the measured OA mass and $N$ is number of data points. The fractional error is calculated using all of the data. Fractional error values are listed in Fig. 5a. Except for the CFM56-JP8-Takeoff and T63-FTGround Idle experiments, the T-SOA module predicts less than half of the measured SOA. T-SOA explains most of the SOA measured during the CFM56-JP8-Takeoff and T63-FTGround Idle experiments probably because the SOA mass yields of Murphy and Pandis (2010) are at the high end of those reported in the literature. Figure S1 plots the ratio of predicted T-SOA to the measured SOA. We hypothesize that the large unexplained SOA is a direct result of S/IVOC oxidation.

\subsection{NT-SOA formed versus S/IVOC reacted}

The NT-SOA is estimated by subtracting the T-SOA prediction from the measured SOA. Except for the T63-FT experiments, NT-SOA accounts for anywhere between 34 and $99 \%$ of the SOA measured in the chamber.

Before applying the NT-SOA models, we first examine the mass balance between the estimated NT-SOA and the estimated mass of reacted S/IVOC. For this calculation, we assume that the SVOC react with the $\mathrm{OH}$ radical with a reactivity of $4 \times 10^{-11} \mathrm{~cm}^{3}$ molecules ${ }^{-1} \mathrm{~s}^{-1}$ and IVOC react with the $\mathrm{OH}$ radical with a reactivity of $3 \times$ $10^{-11} \mathrm{~cm}^{3}$ molecules ${ }^{-1} \mathrm{~s}^{-1}$. To quantify the mass balance, we calculate an effective NT-SOA yield, which is defined as follows:

Effective NT-SOA Yield $=\frac{\text { NT }- \text { SOA formed }}{S / I V O C \text { reacted }}$

Figure 6 plots the effective NT-SOA yield as a function of the OA concentration $\left(C_{\mathrm{OA}}\right)$. There are several important points to make from the plot. First, from a mass balance perspective, the NT-SOA yields are reasonable (i.e. they are less than 1), which means that the amount of NT-SOA formed is less than the amount of S/IVOC reacted. Second, the effective NT-SOA yields are similar to published yield data for speciated IVOCs. For example, Fig. 6 indicates that for the JP8 experiments, the effective NT-SOA yields fall between the measured yields for $n$-dodecane $\left(C_{12}\right)$ and $n$-tridecane $\left(C_{13}\right)$. This is not surprising since the UCM distribution of both the emissions and unburned fuel peak between $C_{11}$ and $C_{15}$ (Corporan et al., 2011; Presto et al., 2011). Finally in 


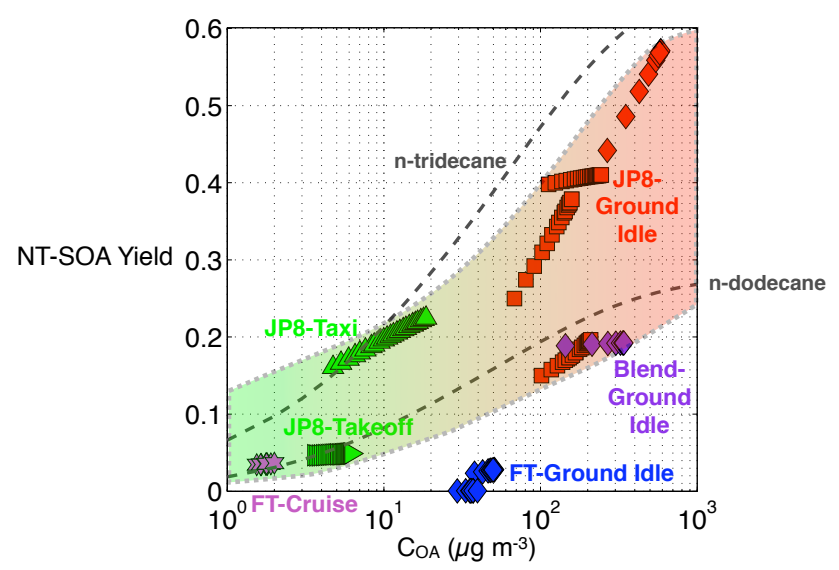

Fig. 6. Estimated NT-SOA yield plotted as a function of $C_{\mathrm{OA}}$. For reference, we also include SOA yields for $n$-dodecane and $n$ tridecane (dotted grey lines) from Presto et al. (2010).

most experiments, the NT-SOA yields increase with increasing $C_{\mathrm{OA}}$, implying that the NT-SOA is semi-volatile, similar to T-SOA formed in smog chamber experiments (Odum et al., 1996).

The effective yields plotted in Fig. 6 also appear to depend on both engine load and fuel composition. First, the groundidle experiments appear to have higher yields than nonground-idle experiments. This could be due to differences in precursor composition; in other words, the ground-idle S/IVOC emissions are comprised of compounds that more efficiently produce SOA than non-ground-idle emissions. If true, then different NT-SOA parameterizations would need to be developed for different engine loads. Alternatively, the higher ground-idle experiment yields may be due to partitioning differences (ground-idle experiments were conducted at higher $C_{\mathrm{OA}}$ ). Second, the NT-SOA yields for JP8-Ground Idle are higher than Blend-Ground Idle yields which are higher than FT-Ground Idle yields. Accounting for differences in $C_{\mathrm{OA}}$, it could be argued that Blend-Ground Idle yields are an arithmetic average of the JP8-Ground Idle and FT-Ground Idle yields. Miracolo et al. (2012) showed that the differences in SOA formation between JP8 and FT could mostly be attributed to compositional differences in the fuels. FT is mainly comprised of branched alkanes, which have low SOA yields versus JP8 which contains similar volatility but higher SOA yield $n$-alkanes and aromatics. Therefore, different NT-SOA parameterizations may be needed for different fuel types.

\subsection{Parameterizing NT-SOA formation}

In this section we develop parameterizations for NT-SOA formation by fitting the measured SOA production. The goal is to determine an optimum parameter-set for the Robinson$2007\left(k_{\mathrm{OH}, \mathrm{M}}, f_{\mathrm{oxy}}\right.$ and $\left.q\right)$ and Hybrid approaches $\left(\alpha_{i, j}\right.$; Eq. 6).

\subsubsection{Robinson-2007 method}

The Robinson-2007 method, when using the Robinson et al. (2007) and Grieshop et al. (2009) parameter sets, underpredicts the NT-SOA formed during ground-idle experiments but over-predicts it during non-ground-idle experiments. Therefore, we fit the NT-SOA data to find an optimum parameter set for the Robinson-2007 method. We considered a wide but realistic range of reaction rates $\left(k_{\mathrm{OH}}\right)$, fraction of oxygen added to the product per reaction $\left(f_{\text {oxy }}\right)$ and shift in volatility $(q)$. For $k_{\mathrm{OH}}$, we use a range of 1 to $5 \times 10^{-11} \mathrm{~cm}^{3}$ molecules ${ }^{-1} \mathrm{~s}^{-1}$ based on Atkinson and Arey (2003). For $f_{\text {oxy }}$, we use a range of 0.05 to 0.4 , which corresponds to the addition of 1 to 5 oxygen atoms per oxidation reaction to a $C_{15}$ alkane. For $q$, we use a value of either 1 or 2 , which corresponds to 1 or 2 orders of magnitude change in the product volatility with each oxidation reaction. Within these ranges, the optimum set was determined by minimizing the fractional error (Eq. 7) between model predictions and measurements for each experiment.

For the ground-idle experiments (except for the FTGround Idle) an aggressive parameter-set $\left(k_{\mathrm{OH}}=3-5 \times\right.$ $10^{-11} \mathrm{~cm}^{3}$ molecules $^{-1} \mathrm{~s}^{-1}, f_{\text {oxy }}=0.05-0.4, q=2$ ) is required to fit the SOA data. In comparison, a more modest parameter-set $\left(k_{\mathrm{OH}}=1-3 \times 10^{-11} \mathrm{~cm}^{3}\right.$ molecules ${ }^{-1} \mathrm{~s}^{-1}$, $\left.f_{\text {oxy }}=0.05-0.3, q=1\right)$ is sufficient to describe the nonground-idle SOA data. The results are illustrated in Fig. 5b, which plots model predictions using the Robinson-2007 method with the best fit for each experiment against the OA measured in the chamber. Compared to predictions from the T-SOA model alone, the model predictions are improved for the CFM56 experiments but only slightly improved for the T63 experiments. The improvement is quantified by the fractional error values listed in Fig. 5.

Although an optimum parameter set provides some improvement over the T-SOA model, the Robinson-2007 method cannot reproduce the temporal trend in the data. The problem is illustrated in Fig. 7, which plots time series of the measured OA. The measured production either varies linearly or rolls over with $\mathrm{OH}$ exposure in the chamber. However, the NT-SOA calculated using the Robinson-2007 method shows the opposite trend with little NT-SOA formed initially and significantly more is formed later. This effect is most clearly seen for the T63-Blend-Ground Idle case plotted in Fig. 8. It occurs because the Robinson-2007 approach requires (given the volatility distribution of the aircraft emissions) several generations of oxidation (a lot of $\mathrm{OH}$ exposure) before a large fraction of the products have a $C^{*}$ low enough to partition into the particle phase. The problem is most severe in the ground-idle experiments where almost all of the emissions are IVOC (Table 2). The Robinson-2007 method works for the CFM56-JP8-Taxi and CFM56-JP8-Takeoff experiments primarily because a sizeable fraction of the emissions are in the lower $C^{*}$ bins $\left(C^{*}=10^{2}-10^{4} \mu \mathrm{g} \mathrm{m}{ }^{-3}\right.$; Table 2). 


\section{POA TSOA NTSOA (1st generation) NTSOA (aged) Measured OA}

CFM56
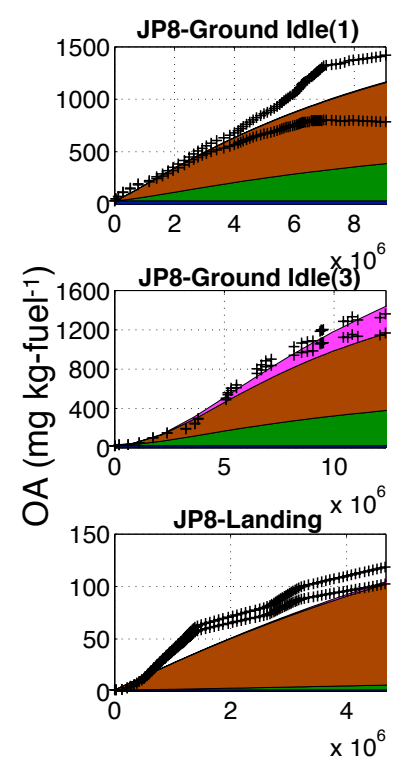
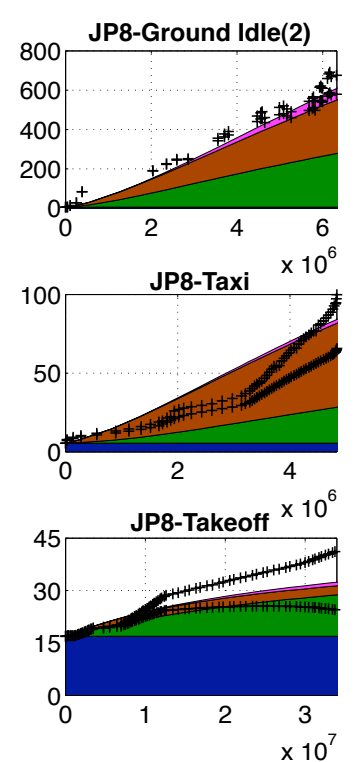

$\mathrm{OH}$ exposure (mo
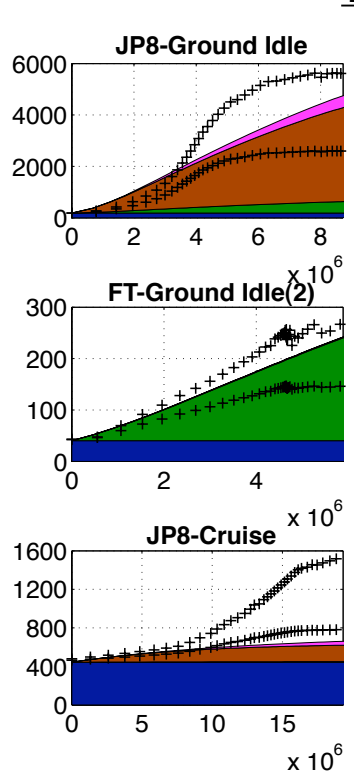

T63
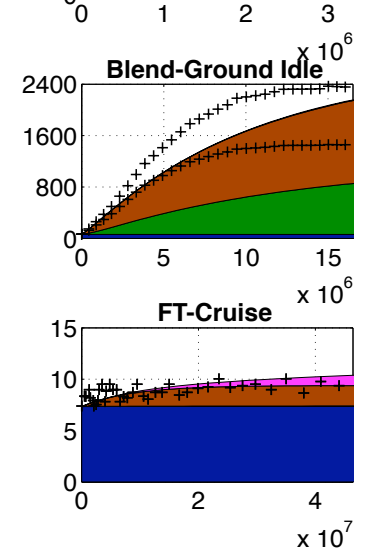

Fig. 7. Model predictions of OA compared to those measured during each experiment. The two sets of symbols for the measured values show the range of uncertainty, as discussed in the text. NT-SOA is predicted using the Hybrid method using best fits for each experiment. For some experiments, $\mathrm{OH}$ concentrations are calculated using intermittent measurements which results in step changes in the $\mathrm{OH}$ exposure. For those experiments, we see sudden changes in SOA formation with $\mathrm{OH}$ exposure.

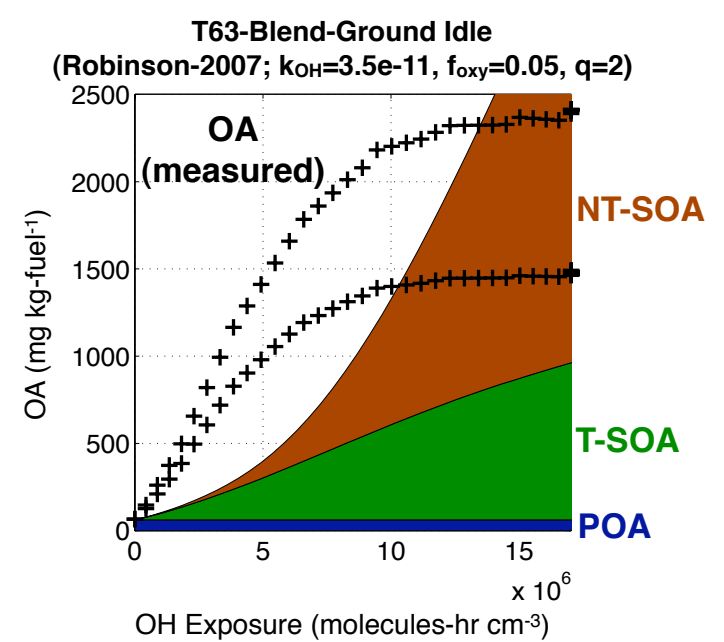

Fig. 8. Measured OA compared to model predictions using bestfits of the Robinson-2007 method for the T63-Blend-Ground Idle experiment. The two sets of symbols for the measured values show the range of uncertainty, as discussed in the text.

Estimates of the $\mathrm{O}: \mathrm{C}$ ratio of the $\mathrm{OA}$ reveals additional problems with the Robinson-2007 method. The O:C of the POA was measured before the oxidation phase of the experiment. For T-SOA, we use the work of Chhabra et al. (2010) to assign the $\mathrm{O}: \mathrm{C}$ for SOA formed from alkenes and aromatics and the work of Presto et al. (2010) to assign the $\mathrm{O}: \mathrm{C}$ for SOA formed from alkanes. For NT-SOA, we calculate $\mathrm{O}: \mathrm{C}$ by explicitly tracking the addition of oxygen per reaction $\left(f_{\text {oxy }}\right)$. For a few of the experiments, the optimum parameter-set for the Robinson-2007 method predicts a very high $\mathrm{O}: \mathrm{C}$ ratio $(>0.8)$ of $\mathrm{OA}$ (much higher than that estimated from the AMS data). This occurs because precursors have to go through multiple generations of oxidation before they reach a low enough volatility to partition into the particle phase. A consequence of this is that a lot of oxygen is added, with the exact amount depending on the values of $f_{\text {oxy }}$ and $q$. For example, for the optimized parameter-set for the T63-JP8-Ground Idle experiment $\left(k_{\mathrm{OH}}=5 \times 10^{-11} \mathrm{~cm}^{3}\right.$ molecules ${ }^{-1} \mathrm{~s}^{-1}, f_{\text {oxy }}=0.40$, $q=2$ ), the $\mathrm{O}: \mathrm{C}$ of the product would be close to 1 after only two generations of oxidation versus 0.32 for the measured data. It is clear that the Robinson-2007 approach is unable to reproduce both the temporal dependence of NT-SOA and the $\mathrm{O}: \mathrm{C}$ of OA.

\subsubsection{Hybrid method}

For each experiment, we fit the NT-SOA data to determine a set of VBS yields (Eq. 6) for the Hybrid method. Figure 7 plots the time series of measured and predicted OA for each 


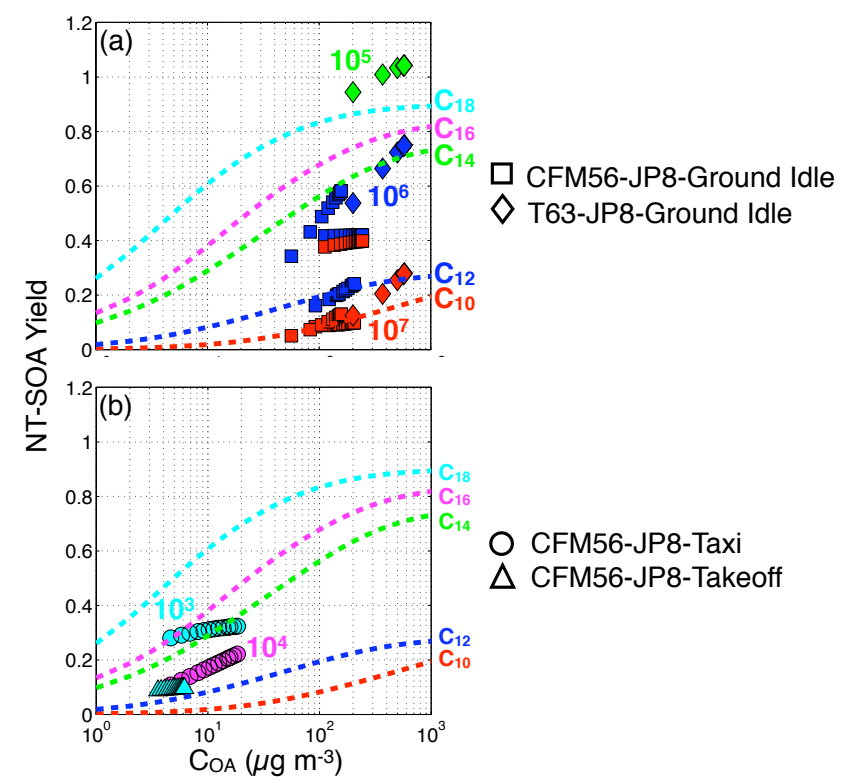

Fig. 9. Estimated SOA yield plotted as a function of $C_{\mathrm{OA}}$ for different S/IVOC volatility bins that contribute more than $15 \%$ of the predicted NT-SOA mass (symbols). For reference, we also plot SOA yields for $n$-decane (estimated), $n$-dodecane, $n$-tetradecane, $n$ hexadecane and $n$-octadecane (estimated) (dotted lines) from Presto et al. (2010). The colors connect the estimate NT-SOA yields for each volatility bin (symbols) to the $n$-alkane with same volatility (dotted lines). For example, the SOA yields for the $C^{*}=$ $10^{6} \mu \mathrm{g} \mathrm{m}^{-3}$ bin for all the experiments are plotted with blue squares and the SOA yield for $C^{*}$ equivalent $n$-dodecane $\left(C_{12}\right)$ is plotted with a blue dotted line.

experiment, with the NT-SOA calculated using the best fit for the Hybrid method. The upper and lower bounds for the measured OA are presented; they are based on the experimental uncertainty due to wall-losses (we have not accounted for uncertainty in the T-SOA model). The predicted contribution from the first generation of oxidation of S/IVOC is labeled "NTSOA (1st generation)" and the contribution from multigenerational oxidation is labeled "NTSOA (aged)". Figure 7 indicates that the multi-generational oxidation - as defined by Eq. (4) - contributes negligibly to the SOA mass over the range of oxidant exposures observed in these experiments. Scatter plots of the model versus measurements are shown in Fig. 5c. The Hybrid method describes the data better than the Robinson-2007 method with significantly lower fractional errors.

To compare the Hybrid method fits across different experiments, Fig. 9 plots the NT-SOA yields for select VBS-bin precursors as a function of $C_{\mathrm{OA}}$ for the JP8 experiments. The NT-SOA yield is defined as the SOA formed by each bin (precursor) divided by the mass of S/IVOC precursor reacted from that bin. Figure 9 a shows yields for the precursors in the $10^{5}, 10^{6}$ and $10^{7} \mu \mathrm{g} \mathrm{m}^{-3}$ bins and Fig. 9b shows yields for precursors in the $10^{3}$ and $10^{4} \mu \mathrm{g} \mathrm{m}^{-3}$ bins. For visual clar-
Table 3. VBS yields for S/IVOC for non-idle and idle emissions.

\begin{tabular}{|c|c|c|c|c|c|c|c|}
\hline \multicolumn{4}{|c|}{ Ground Idle Yields } & \multicolumn{4}{|c|}{ Non-Ground Idle Yields } \\
\hline$a_{1}$ & $b_{1}$ & $c_{1}$ & $d_{1}$ & $a_{1}$ & $b_{1}$ & $c_{1}$ & $d_{1}$ \\
\hline 0.00 & 0.10 & 0.10 & 0.20 & 0.05 & 0.10 & 0.00 & 0.00 \\
\hline
\end{tabular}

ity, we have not plot yields for S/IVOC precursors that contribute less than $15 \%$ to the NT-SOA mass. The lower $C^{*}$ surrogates generally do not contribute much NT-SOA mass because their emissions are either low and/or because very little of their mass exists as vapors and is therefore available for oxidation.

For all of the ground-idle experiments (Fig. 9a), irrespective of the field campaign, almost all of the NT-SOA is produced from the oxidation of IVOC $\left(C^{*}\right.$ bins: $10^{5}, 10^{6}$ and $10^{7} \mu \mathrm{g} \mathrm{m}^{-3}$ ). This is expected because $90 \%$ of the lowvolatility organic emissions are IVOC which peak at $C^{*}=$ $10^{6}$ and $10^{7} \mu \mathrm{g} \mathrm{m}^{-3}$. In contrast, for the non-ground-idle experiments (Fig. 9b), the NT-SOA arises from less volatile S/IVOCs in the $10^{3}$ and $10^{4} \mu \mathrm{g} \mathrm{m}^{-3}$ bins, which contribute a larger fraction of the emissions at higher loads.

Figure 9a shows that the estimated SOA yields for IVOC in the $10^{5}, 10^{6}$ and $10^{7} \mu \mathrm{g} \mathrm{m}^{-3}$ bins (symbols) are equal or higher than published yields for $n$-alkanes in the same $C^{*}$ range (dashed lines; $C_{14} \sim 10^{5} \mu \mathrm{g} \mathrm{m}^{-3}, C_{12} \sim 10^{6} \mu \mathrm{g} \mathrm{m}^{-3}$ and $C_{10} \sim 10^{7} \mu \mathrm{g} \mathrm{m}^{-3}$ ). We believe that the higher yields are due to unburned fuel being a large component of the ground-idle emissions (Presto et al., 2011). JP8 fuel contains significant amounts of cycloalkanes and aromatics which have higher SOA yields than $n$-alkanes. In contrast, Fig. $9 \mathrm{~b}$ shows that the effective SOA yields for S/IVOC in the $10^{3}$ and $10^{4} \mu \mathrm{g} \mathrm{m}^{-3}$ bins (symbols) are lower than the published yields for $n$-alkanes (Presto et al., 2010) in the same $C^{*}$ range (dashed lines; $C_{18} \sim 10^{3} \mu \mathrm{g} \mathrm{m}^{-3}$ and $C_{16} \sim 10^{4} \mu \mathrm{g} \mathrm{m}^{-3}$ ). We hypothesize that S/IVOC emissions during non-ground-idle conditions are dominated by species that have lower SOA yields than similar volatility $n$-alkanes such as branched alkanes (Lim and Ziemann, 2009b, a, 2005; Tkacik et al., 2012) or carbonyls (Chacon-Madrid and Donahue, 2011; Chacon-Madrid et al., 2010).

Given the apparent differences between ground-idle and non-ground-idle experiments, we developed two different parameter sets $\left(\alpha_{i, j}\right)$ for the NT-SOA model for aircraft engines running JP8. Table 3 lists the mass yields for the groundidle and non-ground-idle conditions. The information in Table 3 can be interpreted using the mass-yield matrix defined in Eq. (6). 


\section{Conclusions and discussion}

Many combustion systems emit substantial amounts of S/IVOC vapors (Schauer et al., 2002, 1999, 2001) that cannot be speciated but are likely important SOA precursors. We define the SOA formed from these vapors as NT-SOA. In this paper, we develop a Hybrid method based on the VBS to model SOA formation from unspeciated S/IVOC vapors. Unspeciated S/IVOCs are classified by volatility and then allowed to react with the hydroxyl radical. The Hybrid method distributes the S/IVOC oxidation products over a range of volatilities, with larger reductions in volatility with each oxidation step than previous S/IVOC SOA parameterizations. This volatility operator is more consistent with SOA formation from speciated VOCs (traditional SOA precursors) and with the reductions in volatility caused by the addition of common functional groups. Therefore, compared to previous parameterizations, the Hybrid method provides a more realistic representation of NT-SOA formation from S/IVOCs.

We applied the Hybrid method to SOA data from smog chamber experiments conducted on dilute aircraft exhaust. Speciated VOCs (i.e. traditional precursors) accounted for less than half of the measured SOA in most experiments. The following pieces of evidence suggest that unspeciated S/IVOC vapors were important SOA precursors in these experiments. First, Tenax sorbent measurements demonstrate that the emissions of S/IVOC vapors are substantial, exceeding those of traditional SOA precursors. Second, estimated NT-SOA yields from these vapors are similar to data for individual S/IVOC species. However, the S/IVOC parameterization of Robinson et al. (2007) cannot reproduce the measured evolution of SOA production. The fits developed using the Hybrid method were able to reproduce the temporal evolution of SOA production.

The NT-SOA yields calculated using the Hybrid approach increased with increasing SOA, indicating that NT-SOA is semi-volatile. In addition, the yields appear to depend on both fuel composition and engine load. For example, the effective NT-SOA yield is highest for JP8 and lowest for FT while the 50:50 JP8:FT blend appears to be an average of JP8 and FT. These differences cannot be solely explained by differences in the volatility of the emissions. Therefore, the NT-SOA yields also depend on the molecular structure of the emissions, in addition to volatility influences, consistent with data from single compound smog chamber studies (Lim and Ziemann, 2009b, a; Tkacik et al., 2012). Therefore, different NT-SOA parameterizations may be needed for different fuels and/or different engine loads. Table 3 provides two sets of parameters, one for ground-idle emissions and one for non-ground-idle emissions. These parameters are suitable for use with the VBS framework in any box, plume, regional or global OA model using the emissions data listed in Table 2.

Adding more information on molecular structure of the emissions into the Hybrid method would likely improve model performance. Unfortunately, although progress is be- ing made on UCM characterization (Isaacman et al., 2012), it likely will be many years before we are able to fully characterize the S/IVOC emissions. Volatility-based approaches provide a first step to incorporating unspeciated precursors into SOA models. One concern is that source to source differences in the composition of the emissions may require that unspeciated emissions from each source have different SOA parameterizations, which could complicate implementation of the Hybrid approach in global and regional models. This is an area for future research.

\section{Supplementary material related to this article is available online at: http://www.atmos-chem-phys.net/12/ 9025/2012/acp-12-9025-2012-supplement.pdf.}

Acknowledgements. Funding was provided by the U.S. Department of Defense Strategic Environmental Research and Development Program (SERDP) under project WP-1626. The views, opinions, and/or findings contained in this paper are those of the authors and should not be construed as an official position of any of the funding agency.

Edited by: R. Harley

\section{References}

Atkinson, R. and Arey, J.: Atmospheric degradation of volatile organic compounds, Chem. Rev., 103, 4605-4638, 2003.

Bernstein, J. A., Alexis, N., Barnes, C., Bernstein, I. L., Bernstein, J. A., Nel, A., Peden, D., Diaz-Sanchez, D., Tarlo, S. M., and Williams, P. B.: Health effects of air pollution, The Journal of Allergy and Clinical Immunology, 114, 1116-1123, 2004.

Chacon-Madrid, H. J. and Donahue, N. M.: Fragmentation vs. functionalization: chemical aging and organic aerosol formation, Atmos. Chem. Phys., 11, 10553-10563, doi:10.5194/acp11-10553-2011, 2011.

Chacon-Madrid, H. J., Presto, A. A., and Donahue, N. M.: Functionalization vs. Fragmentation: $\mathrm{N}$-aldehyde oxidation mechanisms and secondary organic aerosol formation, Phys. Chem. Chem. Phys., 12, 13975-13982, doi:10.1039/c0cp00200c, 2010.

Chhabra, P. S., Flagan, R. C., and Seinfeld, J. H.: Elemental analysis of chamber organic aerosol using an aerodyne high-resolution aerosol mass spectrometer, Atmos. Chem. Phys., 10, 4111-4131, doi:10.5194/acp-10-4111-2010, 2010.

Corporan, E., Edwards, T., Shafer, L., DeWitt, M. J., Klingshirn, C., Zabarnick, S., West, Z., Striebich, R., Graham, J., and Klein, J.: Chemical, thermal stability, seal swell, and emissions studies of alternative jet fuels, Energy \& Fuels, 25, 955-966, doi:10.1021/ef101520v, 2011.

Donahue, N., Robinson, A., Stanier, C., and Pandis, S.: Coupled partitioning, dilution, and chemical aging of semivolatile organics, Environ. Sci. Technol, 40, 2635-2643, doi:10.1021/es052297c, 2006. 
Drozd, G. T., Miracolo, M. A., Presto, A. A., Lipsky, E. M., Riemer, D. D., Corporan, E., and Robinson, A. L.: Particulate matter and organic vapor emissions from an in-use helicopter engine operating on petroleum and fischer-tropsch fuels, Energy \& Fuels, 26, 4756-4766, 2012.

Dzepina, K., Volkamer, R. M., Madronich, S., Tulet, P., Ulbrich, I. M., Zhang, Q., Cappa, C. D., Ziemann, P. J., and Jimenez, J. L.: Evaluation of recently-proposed secondary organic aerosol models for a case study in Mexico City, Atmos. Chem. Phys., 9, 5681-5709, doi:10.5194/acp-9-5681-2009, 2009.

Dzepina, K., Cappa, C. D., Volkamer, R. M., Madronich, S., DeCarlo, P. F., Zaveri, R. A., and Jimenez, J. L.: Modeling the multiday evolution and aging of secondary organic aerosol during milagro 2006, Environ. Sci. Technol., 45, 3496-3503, doi:10.1021/es103186f, 2010.

Farina, S. C., Adams, P. J., and Pandis, S. N.: Modeling global secondary organic aerosol formation and processing with the volatility basis set: Implications for anthropogenic secondary organic aerosol, J. Geophys. Res., 115, D09202, doi:10.1029/2009JD013046, 2010.

Goldstein, A. H. and Galbally, I. E.: Known and unexplored organic constituents in the earth's atmosphere, Environ. Sci. Technol., 41, 1514-1521, doi:10.1021/es072476p, 2007.

Grieshop, A. P., Logue, J. M., Donahue, N. M., and Robinson, A. L.: Laboratory investigation of photochemical oxidation of organic aerosol from wood fires 1: measurement and simulation of organic aerosol evolution, Atmos. Chem. Phys., 9, 1263-1277, doi:10.5194/acp-9-1263-2009, 2009.

Heald, C. L., Jacob, D. J., Park, R. J., Russell, L. M., Huebert, B. J., Seinfeld, J. H., Liao, H., and Weber, R. J.: A large organic aerosol source in the free troposphere missing from current models, Geophys. Res. Lett., 32, L18809, doi:10.1029/2005GL023831, 2005.

Hildebrandt, L., Donahue, N. M., and Pandis, S. N.: High formation of secondary organic aerosol from the photo-oxidation of toluene, Atmos. Chem. Phys., 9, 2973-2986, doi:10.5194/acp-92973-2009, 2009.

Hodzic, A., Jimenez, J. L., Madronich, S., Canagaratna, M. R., DeCarlo, P. F., Kleinman, L., and Fast, J.: Modeling organic aerosols in a megacity: potential contribution of semi-volatile and intermediate volatility primary organic compounds to secondary organic aerosol formation, Atmos. Chem. Phys., 10, 5491-5514, doi:10.5194/acp-10-5491-2010, 2010.

IPCC, W.: Climate change 2007: The physical science basis, Summary for Policy Makers, Contribution of Working Group I to the Fourth Assessment Report of the Intergovernmental Panel on Climate Change, 2007.

Isaacman, G., Wilson, K. R., Chan, A. W. H., Worton, D. R., Kimmel, J. R., Nah, T., Hohaus, T., Gonin, M., Kroll, J. H., and Worsnop, D. R.: Improved resolution of hydrocarbon structures and constitutional isomers in complex mixtures using gas chromatography-vacuum ultraviolet-mass spectrometry (gc-vuvms), Anal. Chem., 84, 2335-2342, 2012.

Jathar, S. H., Farina, S. C., Robinson, A. L., and Adams, P. J.: The influence of semi-volatile and reactive primary emissions on the abundance and properties of global organic aerosol, Atmos. Chem. Phys., 11, 7727-7746, doi:10.5194/acp-11-77272011, 2011.

Johnson, D., Utembe, S. R., Jenkin, M. E., Derwent, R. G., Hayman, G. D., Alfarra, M. R., Coe, H., and McFiggans, G.: Simu- lating regional scale secondary organic aerosol formation during the TORCH 2003 campaign in the southern UK, Atmos. Chem. Phys., 6, 403-418, doi:10.5194/acp-6-403-2006, 2006.

Kroll, J. H. and Seinfeld, J. H.: Chemistry of secondary organic aerosol: Formation and evolution of low-volatility organics in the atmosphere, Atmos. Environ., 42, 3593-3624, 2008.

Kroll, J. H., Donahue, N. M., Jimenez, J. L., Kessler, S. H., Canagaratna, M. R., Wilson, K. R., Altieri, K. E., Mazzoleni, L. R., Wozniak, A. S., Bluhm, H., Mysak, E. R., Smith, J. D., Kolb, C. E., and Worsnop, D. R.: Carbon oxidation state as a metric for describing the chemistry of atmospheric organic aerosol, Nature Chem., 3, 133-139, 2011.

Lane, T. E., Donahue, N. M., and Pandis, S. N.: Simulating secondary organic aerosol formation using the volatility basis-set approach in a chemical transport model, Atmos. Environ., 42, 7439-7451, 2008.

Lim, Y. B. and Ziemann, P. J.: Products and mechanism of secondary organic aerosol formation from reactions of n-alkanes with oh radicals in the presence of no x, Environ. Sci. Technol., 39, 9229-9236, 2005.

Lim, Y. B. and Ziemann, P. J.: Effects of molecular structure on aerosol yields from oh radical-initiated reactions of linear, branched, and cyclic alkanes in the presence of no x, Environ. Sci. Technol., 43, 2328-2334, 2009a.

Lim, Y. B. and Ziemann, P. J.: Chemistry of secondary organic aerosol formation from oh radical-initiated reactions of linear, branched, and cyclic alkanes in the presence of no $\mathrm{x}$, Aerosol Sci. Technol., 43, 604-619, 2009b.

Miracolo, M. A., Hennigan, C. J., Ranjan, M., Nguyen, N. T., Gordon, T. D., Lipsky, E. M., Presto, A. A., Donahue, N. M., and Robinson, A. L.: Secondary aerosol formation from photochemical aging of aircraft exhaust in a smog chamber, Atmos. Chem. Phys., 11, 4135-4147, doi:10.5194/acp-11-4135-2011, 2011.

Miracolo, M. A., Drozd, G. T., Jathar, S., Presto, A. A., Lipsky, E., Corporan, E., and Robinson, A.: Fuel composition and secondary organic aerosol formation: Gas-turbine exhaust and alternative aviation fuels, Environ. Sci. Technol., 46, 8493-8501, doi:10.1021/es300350c, 2012.

Morris, R. E., Koo, B., Guenther, A., Yarwood, G., McNally, D., Tesche, T. W., Tonnesen, G., Boylan, J., and Brewer, P.: Model sensitivity evaluation for organic carbon using two multipollutant air quality models that simulate regional haze in the southeastern united states, Atmos. Environ., 40, 4960-4972, 2006.

Murphy, B. and Pandis, S.: Simulating the formation of semivolatile primary and secondary organic aerosol in a regional chemical transport model, Environ. Sci. Technol., 43, 4722-4728, doi:10.1021/es803168a, 2009.

Murphy, B. N. and Pandis, S. N.: Exploring summertime organic aerosol formation in the eastern united states using a regionalscale budget approach and ambient measurements, J. Geophys. Res., 115, D24216, doi:10.1029/2010JD014418, 2010.

Ng, N. L., Kroll, J. H., Keywood, M. D., Bahreini, R., Varutbangkul, V., Flagan, R. C., Seinfeld, J. H., Lee, A., and Goldstein, A. H.: Contribution of first-versus second-generation products to secondary organic aerosols formed in the oxidation of biogenic hydrocarbons, Environ. Sci. Technol., 40, 2283-2297, 2006.

Ng, N. L., Kroll, J. H., Chan, A. W. H., Chhabra, P. S., Flagan, R. C., and Seinfeld, J. H.: Secondary organic aerosol formation 
from m-xylene, toluene, and benzene, Atmos. Chem. Phys., 7, 3909-3922, doi:10.5194/acp-7-3909-2007, 2007.

Odum, J. R., Hoffmann, T., Bowman, F., Collins, D., Flagan, R. C., and Seinfeld, J. H.: Gas/particle partitioning and secondary organic aerosol yields, Environ. Sci. Technol., 30, 2580-2585, 1996.

Pankow, J. F.: An absorption model of gas/particle partitioning of organic compounds in the atmosphere, Atmos. Environ., 28, 185-188, 1994.

Presto, A. A., Miracolo, M. A., Donahue, N. M., and Robinson, A. L.: Secondary organic aerosol formation from high-no $\mathrm{x}$ photooxidation of low volatility precursors: N-alkanes, Environ. Sci. Technol., 44, 2029-2034, 2010.

Presto, A. A., Nguyen, N. T., Ranjan, M., Reeder, A. J., Lipsky, E. M., Hennigan, C. J., Miracolo, M. A., Riemer, D. D., and Robinson, A. L.: Fine particle and organic vapor emissions from staged tests of an in-use aircraft engine, Atmos. Environ., 45, 3603-3612, 2011.

Presto, A. A., Hennigan, C. J., Nguyen, N. T., and Robinson, A. L.: Determination of volatility distributions of primary organic aerosol emissions from combustion systems using thermal desorption gas chromatography mass spectrometry, Aerosol Sci. Technol., 46, 1129-1139, 2012.

Pye, H. O. T. and Seinfeld, J. H.: A global perspective on aerosol from low-volatility organic compounds, Atmos. Chem. Phys., 10, 4377-4401, doi:10.5194/acp-10-4377-2010, 2010.

Robinson, A. L., Donahue, N. M., Shrivastava, M. K., Weitkamp, E. A., Sage, A. M., Grieshop, A. P., Lane, T. E., Pierce, J. R., and Pandis, S. N.: Rethinking organic aerosols: Semivolatile emissions and photochemical aging, Science, 315, 1259-1262, 2007.

Robinson, A. L., Grieshop, A. P., Donahue, N. M., and Hunt, S. W.: Updating the conceptual model for fine particle mass emissions from combustion systems, J. Air Waste Manage. Assoc., 60, 1204-1222, 2010.

Schauer, J. J., Kleeman, M. J., Cass, G. R., and Simoneit, B. R. T.: Measurement of emissions from air pollution sources. 2. C1 through c 30 organic compounds from medium duty diesel trucks, Environ. Sci. Technol, 33, 1578-1587, 1999.

Schauer, J. J., Kleeman, M. J., Cass, G. R., and Simoneit, B. R. T.: Measurement of emissions from air pollution sources. 3. C1-c29 organic compounds from fireplace combustion of wood, Environ. Sci. Technol, 35, 1716-1728, 2001.
Schauer, J. J., Kleeman, M. J., Cass, G. R., and Simoneit, B. R. T.: Measurement of emissions from air pollution sources. 5. C1c32 organic compounds from gasoline-powered motor vehicles, Environ. Sci. Technol, 36, 1169-1180, 2002.

Shakya, K. M. and Griffin, R. J.: Secondary organic aerosol from photooxidation of polycyclic aromatic hydrocarbons, Environ. Sci. Technol., 44, 8134-8139, doi:10.1021/es1019417, 2010.

Shrivastava, M. K., Lane, T. E., Donahue, N. M., Pandis, S. N., and Robinson, A. L.: Effects of gas particle partitioning and aging of primary emissions on urban and regional organic aerosol concentrations, J. Geophys. Res.-Atmos., 113, D18301, doi:10.1029/2007JD009735, 2008.

Tkacik, D. S., Presto, A. A., Donahue, N. M., and Robinson, A. L.: Secondary organic aerosol formation from intermediatevolatility organic compounds: Cyclic, linear, and branched alkanes, Environ. Sci. Technol., 46, 8773-8781, 2012.

Tsimpidi, A. P., Karydis, V. A., Zavala, M., Lei, W., Molina, L., Ulbrich, I. M., Jimenez, J. L., and Pandis, S. N.: Evaluation of the volatility basis-set approach for the simulation of organic aerosol formation in the Mexico City metropolitan area, Atmos. Chem. Phys., 10, 525-546, doi:10.5194/acp-10-525-2010, 2010.

Vutukuru, S., Griffin, R. J., and Dabdub, D.: Simulation and analysis of secondary organic aerosol dynamics in the south coast air basin of california, J. Geophys. Res., 111, D10S12, doi:10.1029/2005JD006139, 2006.

Wey, C., Anderson, B., Hudgins, C., Wey, C., Li-Jones, X., Winstead, E., Thornhill, L., Lobo, P., Hagen, D., and Whitefield, P. Aircraft particle emissions experiment (apex), NASA TM-2006, 2006.

Zhang, Q., Jimenez, J. L., Canagaratna, M. R., Allan, J. D., Coe, H., Ulbrich, I., Alfarra, M. R., Takami, A., Middlebrook, A. M., Sun, Y. L., Dzepina, K., Dunlea, E., Docherty, K., DeCarlo, P. F., Salcedo, D., Onasch, T., Jayne, J. T., Miyoshi, T., Shimono, A., Hatakeyama, S., Takegawa, N., Kondo, Y., Schneider, J., Drewnick, F., Borrmann, S., Weimer, S., Demerjian, K., Williams, P., Bower, K., Bahreini, R., Cottrell, L., Griffin, R. J., Rautiainen, J., Sun, J. Y., Zhang, Y. M., and Worsnop, D. R.: Ubiquity and dominance of oxygenated species in organic aerosols in anthropogenically-influenced northern hemisphere midlatitudes, Geophys. Res. Lett., 34, L13801, doi:10.1029/2007GL029979, 2007. 